\title{
A framework for interpreting functional networks in schizophrenia
}

\author{
Peter C. Williamson ${ }^{1 *}$ and John M. Allman ${ }^{2}$ \\ 1 Tanna Schulich Chair in Neuroscience and Mental Health, University of Western Ontario, London, ON, Canada \\ ${ }^{2}$ Frank P. Hixon Professor of Neurobiology, Division of Biology, California Institute of Technology, Pasadena, CA, USA
}

Edited by:

Vince D. Calhoun, University of New

Mexico, USA

Reviewed by:

John J. Foxe, Albert Einstein College of Medicine, USA

Jessica A. Turner, Mind Research

Network, USA

*Correspondence:

Peter C. Williamson, Tanna Schulich Chair in Neuroscience and Mental

Health, Department of Psychiatry,

University Hospital, London Health

Sciences Centre, 339 Windermere

Road, London, ON N6A 5A5,

Canada.

e-mail:williams@uwo.ca
Some promising genetic correlates of schizophrenia have emerged in recent years but none explain more than a small fraction of cases. The challenge of our time is to characterize the neuronal networks underlying schizophrenia and other neuropsychiatric illnesses. Early models of schizophrenia have been limited by the ability to readily evaluate large-scale networks in living patients. With the development of resting state and advanced structural magnetic resonance imaging, it has become possible to do this. While we are at an early stage, a number of models of intrinsic brain networks have been developed to account for schizophrenia and other neuropsychiatric disorders. This paper reviews the recent voxel-based morphometry (VBM), diffusion tensor imaging (DTI), and resting functional magnetic resonance imaging literature in light of the proposed networks underlying these disorders. It is suggested that there is support for recently proposed models that suggest a pivotal role for the salience network. However, the interactions of this network with the default mode network and executive control networks are not sufficient to explain schizophrenic symptoms or distinguish them from other neuropsychiatric disorders. Alternatively, it is proposed that schizophrenia arises from a uniquely human brain network associated with directed effort including the dorsal anterior and posterior cingulate cortex (PCC), auditory cortex, and hippocampus while mood disorders arise from a different brain network associated with emotional encoding including the ventral anterior cingulate cortex (ACC), orbital frontal cortex, and amygdala. Both interact with the dorsolateral prefrontal cortex and a representation network including the frontal and temporal poles and the fronto-insular cortex, allowing the representation of the thoughts, feelings, and actions of self and others across time.

Keywords: schizophrenia, major depressive disorder, bipolar disorder, functional MRI, voxel-based morphometry, diffusion tensor imaging, default mode network, salience network

\section{INTRODUCTION}

Over 120 years ago, Emil Kraepelin made the distinction between dementia praecox, later to be called schizophrenia, and manicdepressive psychosis, later to be referred to as bipolar disorder. Although the distinction has held up well, some limitations have become evident. Kraepelin's suggestion that patients with dementia praecox tend to cognitively deteriorate while manic-depressive patients recover was probably not accurate as we now know that bipolar patients can experience cognitive difficulties. We also now know that there is an excess of relatives with bipolar disorder in schizophrenic proband families as well as an excess of schizophrenic relatives in bipolar proband families and some susceptibility loci are common to both nosological categories (Goodwin and Jamison, 2007; Lichtenstein et al., 2009). Yet the distinction between schizophrenia and bipolar disorder remains in all diagnostic systems and even advocates of a dimensional approach admit that there are non-shared genetic risk factors for schizophrenia and bipolar disorder (Craddock and Owen, 2010).

Although some promising genetic anomalies have been associated with schizophrenia, none account for more than a small fraction of cases. The challenge of our time is to discover the brain networks underlying schizophrenia and other neuropsychiatric disorders. Almost every region of the brain has been examined in schizophrenic patients with the prefrontal cortex, the anterior cingulate cortex (ACC), temporal structures, the ventral striatum, the thalamus, and the cerebellum most commonly implicated. More than eight models of aberrant cortical-cortical and cortical-subcortical connections between these regions based on pathological, pharmacological, and brain imaging evidence have been proposed. Each provides some explanatory power but none succeed in demonstrating a unique neuronal circuit anomaly in schizophrenia which contrasts with mood disorders (Williamson, 2006).

The early models of schizophrenia were limited by the inability to easily evaluate large-scale brain networks in living patients. Non-human animal models can demonstrate some aspects of psychosis such as dopaminergic hyperresponsivity but fall far short of the phenomenology of schizophrenia because nonhumans do not have recursive language or the ability to represent the thoughts, feelings, and actions of self and others 
across time. Schizophrenia and bipolar disorders are human disorders (Williamson and Allman, 2011). That changed when it became possible to examine large-scale brain networks with lowfrequency spontaneous fluctuations of the blood oxygen leveldependent signal (lfMRI). Two anticorrelated networks emerged with this approach - a task-related network associated with attention-demanding tasks and the default mode network associated with stimulus-independent thought in the resting state. The task-related network included mostly frontal and parietal regions while the default mode network included the posterior medial cortices and the ventral and dorsal medial prefrontal cortices (Fox et al., 2005; Fransson, 2005). Subsequently, it became clear that there were multiple resting intrinsic brain networks which could be demonstrated with independent component analysis (ICA) (De Luca et al., 2006; Calhoun et al., 2008).

Williamson (2007) proposed that anomalies in coordination of the default mode and task-related circuits could underlie the pathophysiology of schizophrenia. Subsequently it was proposed that anomalies in the coordination of these networks in schizophrenia were related to a third intrinsic network, the salience network, involving the dorsal anterior cingulate and the fronto-insular cortex (Menon, 2011; Palaniyappan and Liddle, 2012). Menon (2011) took this a step further and suggested that the psychopathology of most major conditions such as schizophrenia, major depression, autism, and anxiety disorders could be accounted for by aberrant intrinsic organization and interconnectivity of the salience network, the default mode network and the central executive network, which is similar to the task-related network. In schizophrenia, structural and functional networks were proposed to affect all three networks. Major depression was suggested to be associated with excessive coupling between the salience and default mode networks leading to an inability to cycle out of internal mental processes to attend to salient tasks.

Others have proposed somewhat different pathways underlying psychopathology. Buckner et al. (2008) proposed two brain systems, the default network and a medial temporal lobe system. The default mode was related to internally focussed tasks such as autobiographical memory, envisioning the future, and conceiving the perspectives of others while the temporal system provided information about prior experience for mental simulations in the medial regions. Integration of information occurs with the convergence of the two networks through the posterior cingulate cortex (PCC). Autism was attributed to anomalies in the development of the default network and schizophrenia was attributed to over-activity in the default mode network. Northoff and Qin (2011) suggested that auditory verbal hallucinations in schizophrenia arise from elevated resting state activity in the auditory cortex which might be related to abnormal modulation of the auditory cortex by anterior cortical midline structures associated with the default mode network. Abnormal resting state activity was also suggested to impact stimulusinduced neural activity in medially situated core systems for self-representation in major depression leading to a "highjacking" of higher cortical affective and cortical functions by lower sub-cortical primary-process emotional systems (Northoff et al., 2011).
Williamson and Allman (2011) proposed that neuronal circuits underlying neuropsychiatric disorders mirror unique human capabilities. Brain structures such as the frontal pole, temporal pole, and fronto-insular cortex are highly developed in humans and are likely associated with the representation of the thoughts, feelings, and actions of self and others across time (Damasio et al., 2004; Gilbert et al., 2006; Frith, 2007; Craig, 2009). In the human brain, representational networks interact with other networks involved in directed effort and emotional encoding which have also undergone unique adaptations in the human brain. All three networks interact with the dorsolateral prefrontal cortex allowing the temporal flow of information and behavior. A failure of the representational networks could lead to autism. Schizophrenia was proposed to be related to a failure of the directed effort network which included the dorsal and posterior anterior cingulate cortices, the auditory cortex, and the hippocampus to synchronize with the representational network. Major depression and bipolar disorders were suggested to be associated with a failure of the emotional encoding network, including orbital prefrontal cortex, ventral ACC, and amygdala, to synchronize with the representational network (Williamson and Allman, 2011; Figure 1).

Thus, a number of large-scale brain networks have been proposed to underlie schizophrenia and major psychiatric conditions. All models include the default mode network. The salience network models (Menon, 2011; Palaniyappan and Liddle, 2012) emphasize anomalies in this network in coordinating activity between the task-related and default mode networks in schizophrenia and other neuropsychiatric conditions. Buckner et al. (2008) propose a different emphasis on the temporal systems, the default mode network and their integration through the PCC. The central role of the dorsal anterior cingulate, posterior cingulate, and temporal structures in schizophrenia can also be seen in the Northoff and Qin (2011) and Williamson and Allman (2011) models. These models can be tested. If there are anomalies in these networks in schizophrenia, they should be demonstrable with voxel-based morphometry (VBM), diffusion tensor imaging (DTI), and lfMRI, which open a window on the morphological and functional characteristics of large-scale networks. The purpose of this paper is to examine the more recent literature utilizing these techniques in schizophrenia and mood disorders in light of these models.

\section{VBM \\ FINDINGS IN SCHIZOPHRENIA}

There are now several meta-analyses of findings in well over 1000 schizophrenic patients. There is an emerging consensus that schizophrenic patients have gray matter reductions in the left medial and superior temporal gyrus, left middle frontal gyrus, ACC, bilateral insular cortex, and thalamus although losses have also been reported in inferior prefrontal and posterior regions (Honea et al., 2005; Ellison-Wright et al., 2008; Glahn et al., 2008; Fornito et al., 2009b; Segall et al., 2009; Ellison-Wright and Bullmore, 2010). Particularly noteworthy are the volume reductions in the ACC which may precede the onset of psychosis in high-risk individuals and are accompanied by reductions in neuronal, synaptic, and dendritic density in post-mortem studies 


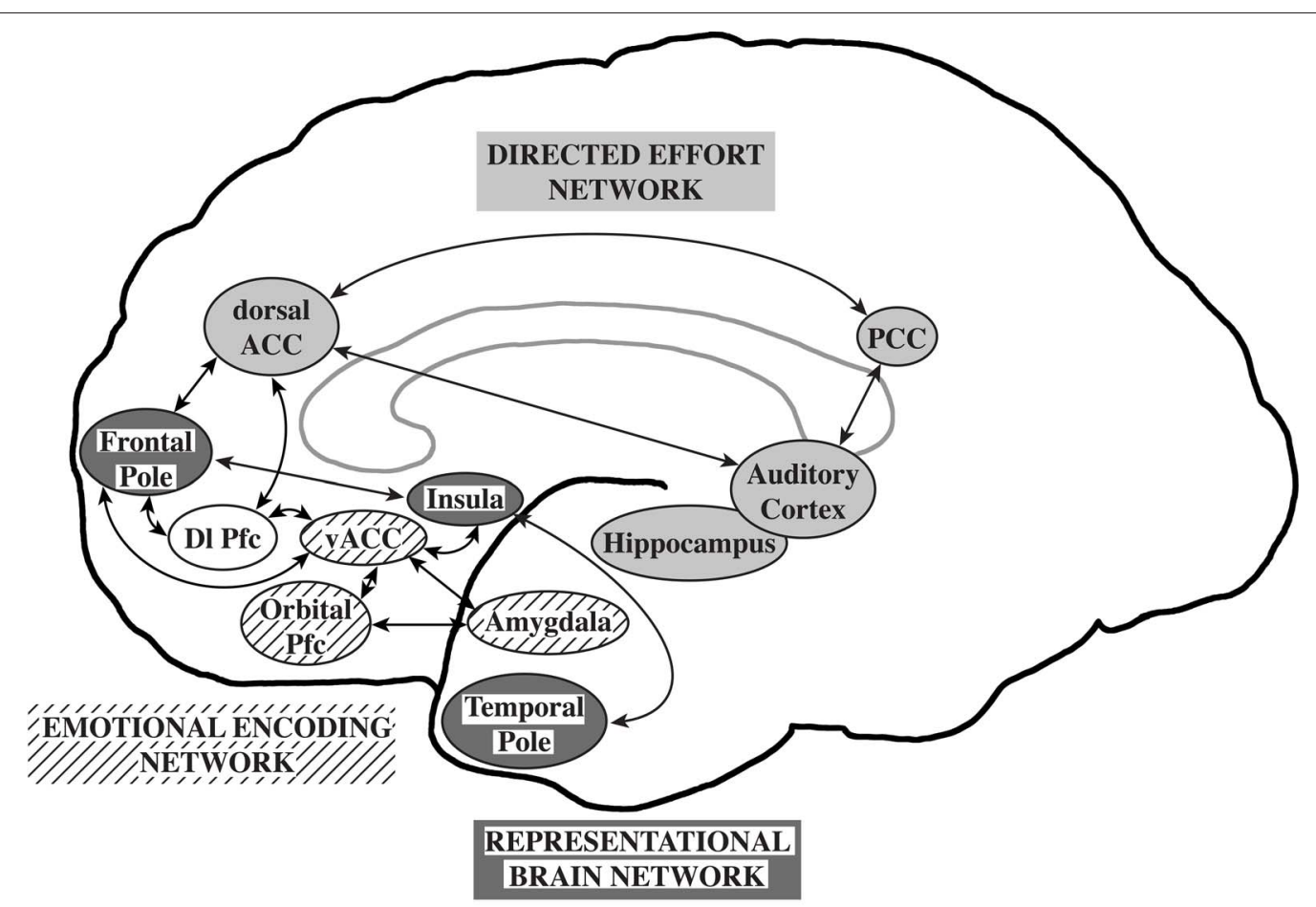

FIGURE 1 | The representational brain. The representational brain network (dark gray), proposed to underlie autism, includes the frontal pole, insula, and temporal pole. The directed effort network (light gray), proposed to underlie schizophrenia, includes the dorsal anterior cingulate cortex (ACC), posterior cingulate cortex (PCC), auditory cortex, and hippocampus. The emotional encoding network (lined), proposed to underlie mood disorders, includes the orbital prefrontal cortex (Pfc), ventral anterior $\mathrm{ACC}$, and amygdala. The directed effort and emotional encoding networks interact with the representational network and the dorsolateral prefrontal cortex (DI PfC, not shaded). Reprinted with permission from Williamson and Allman. The Human IIInesses: Neuropsychiatric Disorders and the Nature of the Human Brain. New York, NY: Oxford University Press, Copyright 2011.
(Baiano et al., 2007). Some brain abnormalities can be seen in first episode patients (Vita et al., 2006; Fornito et al., 2009a) but there is now overwhelming evidence of that gray matter losses in regions associated with task performance such as the prefrontal, parietal, and temporal cortices become more prominent after several years of illness (DeLisi, 2008; Olabi et al., 2011). Significantly greater frontal, temporal, and parietal gray matter losses in childhood-onset schizophrenic patients have been reported compared to patients with transient psychosis and behavior problems who had similar neuroleptic exposure on follow-up (Gogtay et al., 2004) but it is possible that neuroleptic medications may account for some of the differences (Torrey, 2002; Navani and Dazzan, 2008; Smieskova et al., 2009; Ho et al., 2011).

The widespread nature of gray matter losses in schizophrenia has always been difficult to explain. However, both the salience models (Menon, 2011; Palaniyappan and Liddle, 2012) and the extended models (Buckner et al., 2008; Northoff and Qin, 2011; Williamson and Allman, 2011) involving the dorsal anterior and posterior cingulate, and temporal structures would predict this. If salience network fails to appropriately engage the executive control and default mode networks, decreased gray matter activity and potentially loss would be expected. Similarly a failure of the directed effort network would be expected to be associated with widespread gray matter loss by virtue of connections with basal ganglia-thalamocortical networks which effect action via glutamatergic cortical-subcortical pathways (Williamson, 2006). However, the volume reductions in the anterior cingulate, which may precede the onset of psychosis in high risk individuals, points more to the anterior cingulate as the primary cause of the later more widespread changes. The anterior cingulate is closely connected to the posterior cingulate, temporal structures and the insula, implicating all models. The finding that may be difficult for the Williamson and Allman (2011) model to account for is the inferior frontal gray matter loss. However, this might be explained by the reciprocal relationship between the dorsal ACC and inferior prefrontal regions (Mayberg et al., 1999). Reciprocal changes in parallel networks including the representational and emotional encoding networks would be expected.

\section{FINDINGS IN MOOD DISORDERED PATIENTS}

There has been considerable heterogeneity in VBM in patients with major depressive and bipolar disorders (Campbell et al., 2004; Haldane and Frangou, 2004; McDonald et al., 2004; Videbech and Ravnkilde, 2004; Strakowski et al., 2005; Hajek et al., 2008; Savitz and Drevets, 2009; Bora et al., 2010; EllisonWright and Bullmore, 2010). However, there is a recurrent theme of elevated activity and volume loss in the hippocampus, orbital, and ventral prefrontal cortex in patients with major depressive disorder and bipolar disorder (Savitz and Drevets, 2009). The amygdala in contrast is often found to be increased in volume in 
older bipolar patients and either decreased or unchanged in major depressive disorder. Volume losses, particularity in ventral prefrontal regions, are more evident in patients with a positive family history of mood disorders (Hajek et al., 2008). Although there is some overlap with regions showing deficits in schizophrenia, the pregenual cingulate cortex (anterior Brodmann area 24) was found to be reduced in studies of bipolar but not schizophrenic patients (Bora et al., 2010). Interestingly, treatment with mood stabilizing agents has been associated with enlargement of gray matter volumes (Nakamura et al., 2007). Treatment with lithium has been associated with a more selective increase in regions which were found to be reduced in bipolar patients (Bora et al., 2010).

These studies suggest that mood disordered patients demonstrate a pattern of VBM changes predominately in the orbital and ventral prefrontal regions and amygdala. Structural changes in these regions differ from the pattern in schizophrenia and are consistent with the Williamson and Allman (2011) and Northoff et al. (2011) models. The Menon (2011) model has more difficulty accounting for these changes. If there is excessive coupling of the salience network and default mode network in mood disorders, the specific structural changes in the orbital and ventral prefrontal regions which are not part of the salience network or the default mode network would not be expected. Structural changes in the salience network might be expected and they do not seem to be found.

\section{DTI}

\section{FINDINGS IN SCHIZOPHRENIC PATIENTS}

DTI has been applied widely in schizophrenia research (Kanaan et al., 2005; Kubicki et al., 2007; Kyriakopoulis et al., 2008; White et al., 2008; Ellison-Wright and Bullmore, 2009; Bora et al., 2011; Patel et al., 2011). Fractional anisotropy (FA) or the degree to which diffusion is directionally hindered is the most widely used index of white matter integrity in these studies. As in the morphometry studies, considerable heterogeneity has been found. However, most studies have found widespread FA reductions in the cingulate bundle, corpus callosum, and frontal and temporal white matter. In a careful meta-analysis of the co-ordinates of FA differences, significant FA reductions were present in predominantly two regions: the left frontal deep white matter and the left temporal deep white matter (Ellison-Wright and Bullmore, 2009). In the left frontal lobe, the white matter tracts involved interconnected the frontal lobe, thalamus, and cingulate gyrus while in the temporal lobe the white matter tracks involved interconnected the frontal lobe, insula, hippocampus-amygdala, temporal, and occipital lobe. Although FA deficits are present in many first episode, never-treated patients, there is some evidence of progressive deterioration (Mori et al., 2007; Cheung et al., 2008; Zou et al., 2008b; Lee et al., 2009; White et al., 2011). FA anomalies have been associated with chronic illness, negative symptoms, and hallucinations (Seok et al., 2007; Shergill et al., 2007; Skelly et al., 2008; White et al., 2008; Rotarska-Jagiela et al., 2009; Bora et al., 2011).

White matter anomalies in tracts connecting frontal lobe, thalamus, and cingulate gyrus would be consistent with hypothesized dysfunction of the directed effort network in the Williamson and
Allman (2011) model. Directed effort requires action mediated by basal ganglia-thalamocortical networks that include these structures. White matter changes in the temporal lobe interconnecting the frontal lobe, insula, and hippocampus-amygdala would also be consistent with this model and the Buckner et al. (2008) model. Both models emphasize connections between the brain regions associated with mental simulations and the temporal lobes. The salience models might be expected to be associated with anomalies in tracts connecting the cingulate cortex and insula with task-activated and default mode regions but connections to the hippocampus and thalamus are better accounted for by a deficit in the directed effort network. All models would have difficulty accounting for the occipital anomalies.

\section{FINDINGS IN MOOD DISORDERED PATIENTS}

Never-treated and medicated patients with major depressive disorder have demonstrated the ACC and medial prefrontal FA deficits but studies have been inconsistent with deficits also noted in the internal capsule, inferior parietal lobe, occipital lobe, and temporal regions (Li et al., 2007; Ma et al., 2007; Zou et al., 2008a; Abe et al., 2010; Cullen et al., 2010; Korgaonkar et al., 2011; Wu et al., 2011; Zhou et al., 2011). However, a hypothesis driven study demonstrated lower FA in the white matter tract connecting the right subgenual ACC with the right amygdala (Cullen et al., 2010). Most but not all studies have reported association between severity of symptoms and FA deficits (Li et al., 2007; Zou et al., 2008a; Korgaonkar et al., 2011; Zhou et al., 2011). A recent meta-analysis of 10 studies of bipolar disorders identified two significant clusters of decreased FA on the right side. The first was located in the parahippocampal gyrus and the second was located close to the subgenual ACC (Vedrine et al., 2011). Some of these anomalies may be state-dependent (Zanetti et al., 2009; Benedetti et al., 2011).

While there is considerable heterogeneity, the most consistent DTI findings in mood disordered patients involve the subgenual ACC and the amygdala, a pattern which contrasts with that found in schizophrenic patients. The Menon (2011) model does not provide a good explanation for this finding. If the salience network and default mode networks are excessively coupled, one would not predict anomalous connections between the subgenual prefrontal cortex and amygdala. However, the Williamson and Allman (2011) model would predict this as these are key nodes of the emotional encoding network. The Northoff et al. (2011) model would predict subgenual anterior cingulate anomalies but not necessarily anomalies in connections with the amygdala. Thus, the majority of DTI anomalies involve regions involved in emotional encoding although studies are limited and there have been few direct comparisons between mood disordered and schizophrenic patients.

\section{IfMRI INTRINSIC NETWORKS FINDINGS IN SCHIZOPHRENIA}

Task-related network deficits have long been associated with schizophrenia (Williamson, 2006, 2007). However, there is evidence that the default mode network may be abnormal in schizophrenia as well. Unfortunately, the first three studies published within a few months of each other produced somewhat 
inconsistent results. Zhou et al. (2007a) showed reduced functional connectivity between the bilateral dorsolateral prefrontal cortices and the parietal lobe, PCC, thalamus, and striatum in schizophrenic patients. Enhanced functional connectivity was found between the left dorsolateral prefrontal cortex and the left mid-posterior temporal lobe, and paralimbic regions. Garrity et al. (2007) reported spatial differences in the default mode network, particularly in the frontal, anterior cingulate, and parahippocampal gyri. Bluhm et al. (2007) found that schizophrenic patients had significantly less correlation between the spontaneous slow activity in the PCC and that in the lateral parietal, medial prefrontal, and cerebellar regions using a seed-based technique.

There are now numerous studies suggesting anomalies in the default network and other intrinsic networks in schizophrenia which have been reviewed elsewhere (Williamson, 2007; Greicius, 2008; Broyd et al., 2009; Calhoun et al., 2009). The subsequent literature has also been inconsistent but the majority of studies have shown reduced task-related suppression of the default network (Zhou et al., 2007b, 2008; Jafri et al., 2008; Pomarol-Clotet et al., 2008, 2010; Bluhm et al., 2009a; Jann et al., 2009; Kim et al., 2009; Park et al., 2009; Whitfield-Gabrieli et al., 2009; Hoptman et al., 2010; Ke et al., 2010; Lui et al., 2010; Lynall et al., 2010; Mannell et al., 2010; Rotarska-Jagiela et al., 2010; Welsh et al., 2010; White et al., 2010; Hasenkamp et al., 2011; Jang et al., 2011; Repovs et al., 2011; Schneider et al., 2011; Swanson et al., 2011; Wang et al., 2011). Both increased and decreased connectivity has been found in the default network. The amplitude of low-frequency fluctuations (ALFF) have been reported to be decreased in nevertreated patients in medial prefrontal regions (Huang et al., 2010). ALFF normalizes with antipsychotic therapy (Lui et al., 2010; Sambataro et al., 2010).

Garrity et al. (2007) reported that activity in the medial prefrontal, temporal, and cingulate gyri correlated with positive symptoms while Bluhm et al. (2009a) found that patients with positive symptoms showed increased connectivity between the retrosplenial cortex and auditory processing regions. RotarskaJagiela et al. (2010) reported that aberrant functional connectivity in the default mode network correlated with the severity of hallucinations and decreased hemispheric separation of fronto-parietal activity correlated with disorganization symptoms. Patients who have persistent auditory verbal hallucinations (Wolf et al., 2011) have been reported to have increased connectivity in bilateral temporal regions and decreased connectivity in the cingulate cortex within the speech-related network. In networks associated with attention and executive control, patients demonstrated abnormal connectivity in the precuneus and right lateral prefrontal areas. Auditory verbal hallucination severity correlated with the functional connectivity in the left lateral cingulate, left superior temporal gyrus, and right lateral prefrontal cortex.

Why are the findings so inconsistent in schizophrenic patients? Part of the problem may be different analysis techniques. Seedbased and independent component analyses do not always produce the same result. Another reason may be that the default network is not one network but likely scores of networks; only a few of which might be affected at any point of illness or in any particular individual. Resting network activity is also found during some tasks and there appears to be a pattern of reduced distal and enhanced local connectivity in cognitive control networks in schizophrenic patients which correlates with cognitive performance (Repovs et al., 2011). Other brain networks are likely involved as well. Intrinsic network anomalies have been reported in basal-ganglia thalamocortical networks and language and auditory networks (Welsh et al., 2010; Liemburg et al., 2012). Salience network anomalies were reported in one study (White et al., 2010) but no differences were observed in the salience network in another study (Woodward et al., 2011).

Interestingly, schizophrenic patients appear to activate circuits normally involved in retrieving other-related information when processing self-generated information (see Figure 2; Wang et al., 2011). Failure to deactivate default mode regions has been found to correspond to gray matter losses in the dorsal ACC and medial prefrontal regions and DTI anomalies in medial prefrontal and hippocampal connectivity (see Figures 3 and 4; Zhou et al., 2008; Pomarol-Clotet et al., 2010; Skudlarski et al., 2010; Salgado-Pineda et al., 2011). Skudlarski et al. (2010) reported that DTI connectivity was nearly uniformly decreased in schizophrenic patients, functional connectivity was lower in

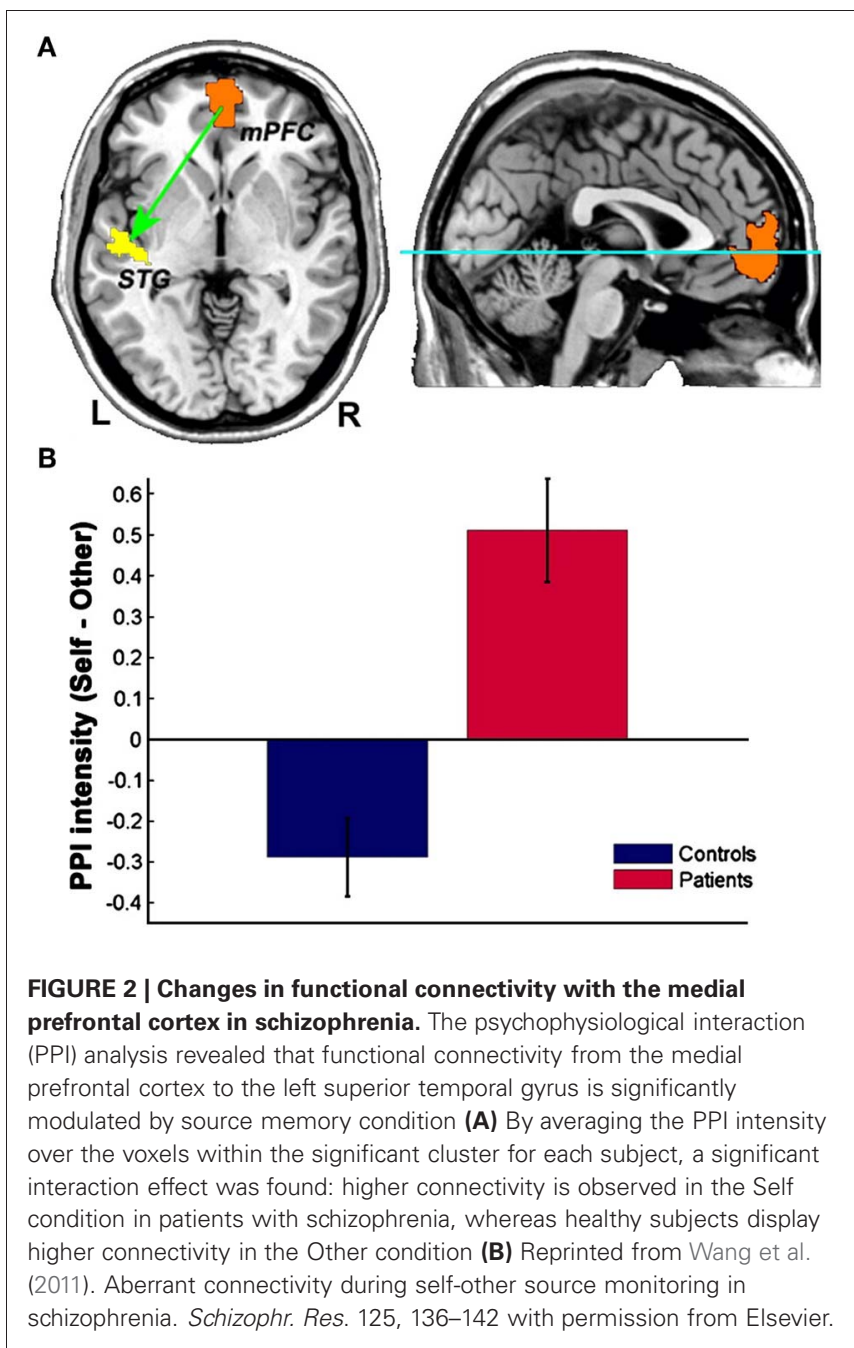




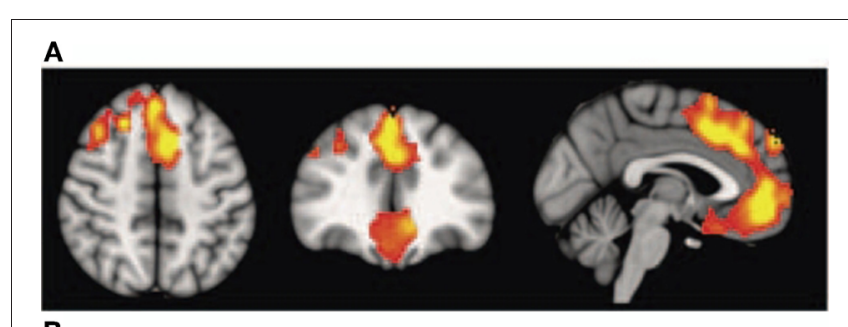

B

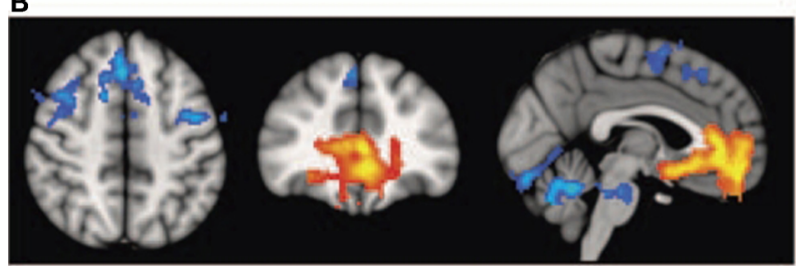

FIGURE 3 | Top panel: (A) Voxel-based morphometry (VBM) findings. Regions showing significant volume reduction thresholded at $p=0.01$ in the schizophrenic patients are shown in orange. Bottom panel:

(B) functional magnetic resonance imaging (fMRI) findings. Regions are shown where there were significant differences between patients and controls during performance of the n-back task (2-back versus baseline comparison), thesholded at $P=0.01$. Blue indicates hypoactivation, that is, areas where controls activated significantly more than patients. Orange indicates areas where the schizophrenic patients showed failure to deactivate in comparison to controls. The right side of the images represents the left side of the brain. Reprinted from Pomarol-Clotet et al (2010). Medial prefrontal cortex pathology in schizophrenia as revealed by convergent findings from multimodal imaging. Mol. Psychiatry 15, 823-830 with permission from Macmillan Publishers Limited.

the middle temporal gyrus and higher in the cingulate and thalamus. Schizophrenic patients also showed decoupling between structural and functional connectivity that could be localized to networks originating in the PCC as well as the task-related network in this study.

In summary, there appears to be agreement that schizophrenic patients have difficulties deactivating the default mode network. However, both increased and decreased connectivity have been reported within the default network, perhaps reflecting of reduced distal and enhanced local connectivity in cognitive control networks in schizophrenic patients (Repovs et al., 2011). Findings in the dorsal anterior cingulate and medial prefrontal cortex are prominent and may correlate with structural anomalies on VBM and DTI (Zhou et al., 2008; Pomarol-Clotet et al., 2010; Skudlarski et al., 2010; Salgado-Pineda et al., 2011). From these studies it is also apparent that many networks are abnormal in schizophrenia in addition to the default mode network. Anomalies in the language networks and basal gangliathalamocortical networks have been reported (Welsh et al., 2010; Liemburg et al., 2012) but findings in the salience network are mixed (White et al., 2010; Woodward et al., 2011).

How do intrinsic network findings relate to the proposed models of schizophrenia? On the whole, they are consistent with the extended models of large-scale network anomalies in schizophrenia. The dorsal anterior and posterior cingulate and auditory cortex are key nodes of the directed effort network (Williamson and Allman, 2011). However, there is support for the Buckner et al.

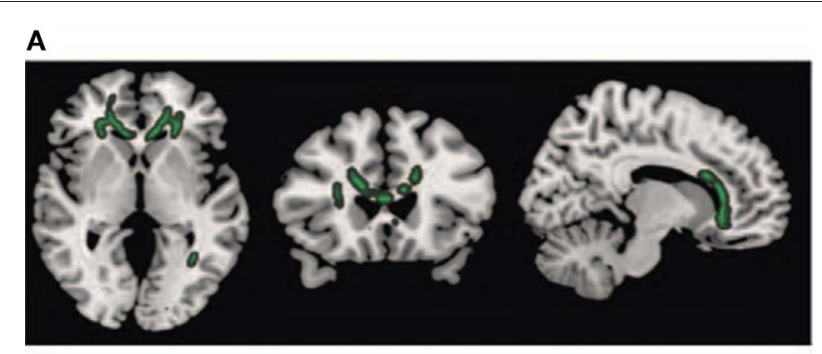

B
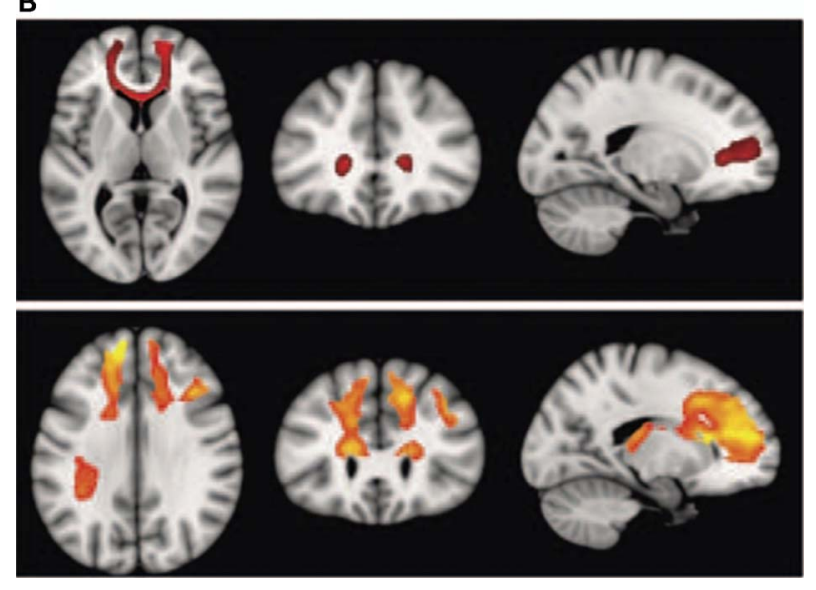

FIGURE 4 | Diffusion tensor imaging (DTI) findings. Top panel:

(A) shows areas of significant fractional anisotropy (FA) reduction in the schizophrenic patients identified using Tract-based Spatial Statistics analysis thresholded at $p=0.01$. Bottom panels $(\mathbf{B})$ show areas of structural connectivity that differed significantly between the schizophrenic patients and controls, on the basis of the seed placed in the genu of the corpus callosum (upper, shown in red), and the seeds placed in the body of the corpus callosum, right and left (lower, shown in orange). A threshold of $p=0.05$ corrected was used for this analysis. The right side of the image represents the left side of the brain. Reprinted from Pomarol-Clotet et al. (2010). Medial prefrontal cortex pathology in schizophrenia as revealed by convergent findings from multimodal imaging. Mol. Psychiatry 15, 823-830 with permission from Macmillan Publishers Limited.

(2008) and Northoff and Qin (2011) models in that temporal and PCC and language processing regions are associated with connectivity abnormalities. In our view the salience models do not fare quite so well. There is no clear-cut abnormality in the salience network to date although this may remain to be determined. A further difficulty is the obvious involvement of other networks such as the language network which does not fit easily into the three networks proposed by Menon (2011).

\section{FINDINGS IN MOOD DISORDERED PATIENTS}

Resting state abnormalities have been reported in both major depressive and bipolar disorder patients (Greicius, 2008; Broyd et al., 2009; Hasler and Northoff, 2011). Major depressive disorder patients have been found to have both increased and decreased connectivity in the default mode network but differences from comparison subjects most often included subgenual and reward processing regions (Greicius et al., 2007; Bluhm et al., 2009b; Cullen et al., 2009; Grimm et al., 2009, 2011; Sheline et al., 2009, 2010; Veer et al., 2010; Berman et al., 2011; Hamilton et al., 2011; 
Peng et al., 2011; Zhang et al., 2011). Bipolar disorder patients also demonstrated anomalies in resting networks mostly involving ventral prefrontal connections to the amygdala (Calhoun et al., 2008; Anand et al., 2009; Chepenik et al., 2010; Dickstein et al., 2010; Öngür et al., 2010; Sui et al., 2011). Selective serotonin reuptake inhibitor administration has been indicated to reduce resting state functional connectivity in the dorso-medial prefrontal cortex (McCabe et al., 2011). Consequently some differences may be associated with medication effects but, on the whole, mood disordered patients present a different pattern of intrinsic network anomalies affecting predominately but not exclusively emotional encoding regions.

Few studies have examined both bipolar and schizophrenic patients. However, subgenual and medial prefrontal anomalies were reported in bipolar patients and dorsal medial prefrontal anomalies in schizophrenic patients in a recent study of both disorders (see Figures 5 and 6; Öngür et al., 2010). In a subsequent seed-based analysis of largely the same data, distinctive patterns emerged. The bipolar group had positive correlations between the medial prefrontal cortex and insular and ventral prefrontal regions. Both schizophrenic and bipolar patients failed to exhibit significant anticorrelation between the medial prefrontal cortex and dorsolateral prefrontal cortex seen in controls, perhaps accounting for cognitive deficits seen in both disorders (Chai et al., 2011).

Although preliminary, there have been some attempts to utilize intrinsic network differences to classify patients on the basis of ICA analysis. It is difficult to translate these components into particular functional networks because of the complex nature of comparisons but differences have been found to have a sensitivity and specificity of 90 and 95\%, respectively, classifying schizophrenia and bipolar disorder on the basis of resting networks (Calhoun et al., 2008). A more recent study (Calhoun et al., 2012) reported that bipolar patients showed more prominent changes in the ventromedial and prefrontal default mode regions while schizophrenic subjects showed differences mostly in posterior default mode regions. The ventral ACC was one of the few regions that distinguished schizophrenic from bipolar disorder patients. The medial prefrontal cortex and ACC were less connected to inferior frontal and insular regions in both schizophrenic patients and bipolar patients. "Fusing" resting data with DTI was also associated with promising levels of discrimination between schizophrenic and bipolar disorder (Sui et al., 2011).

These studies suggest that the pattern of intrinsic functional connectivity is different in bipolar disorder than in schizophrenia. Bipolar disorder patients are more likely to show ventral prefrontal anomalies while schizophrenic patients are more likely to have dorsal anterior cingulate and prefrontal cortex anomalies. This is in keeping with the Williamson and Allman (2011) model, although it is also consistent with Northoff et al. (2011). The finding of predominantly posterior default mode differences in schizophrenic patients would be consistent with both the Williamson and Allman (2011) and Buckner et al. (2008) models.

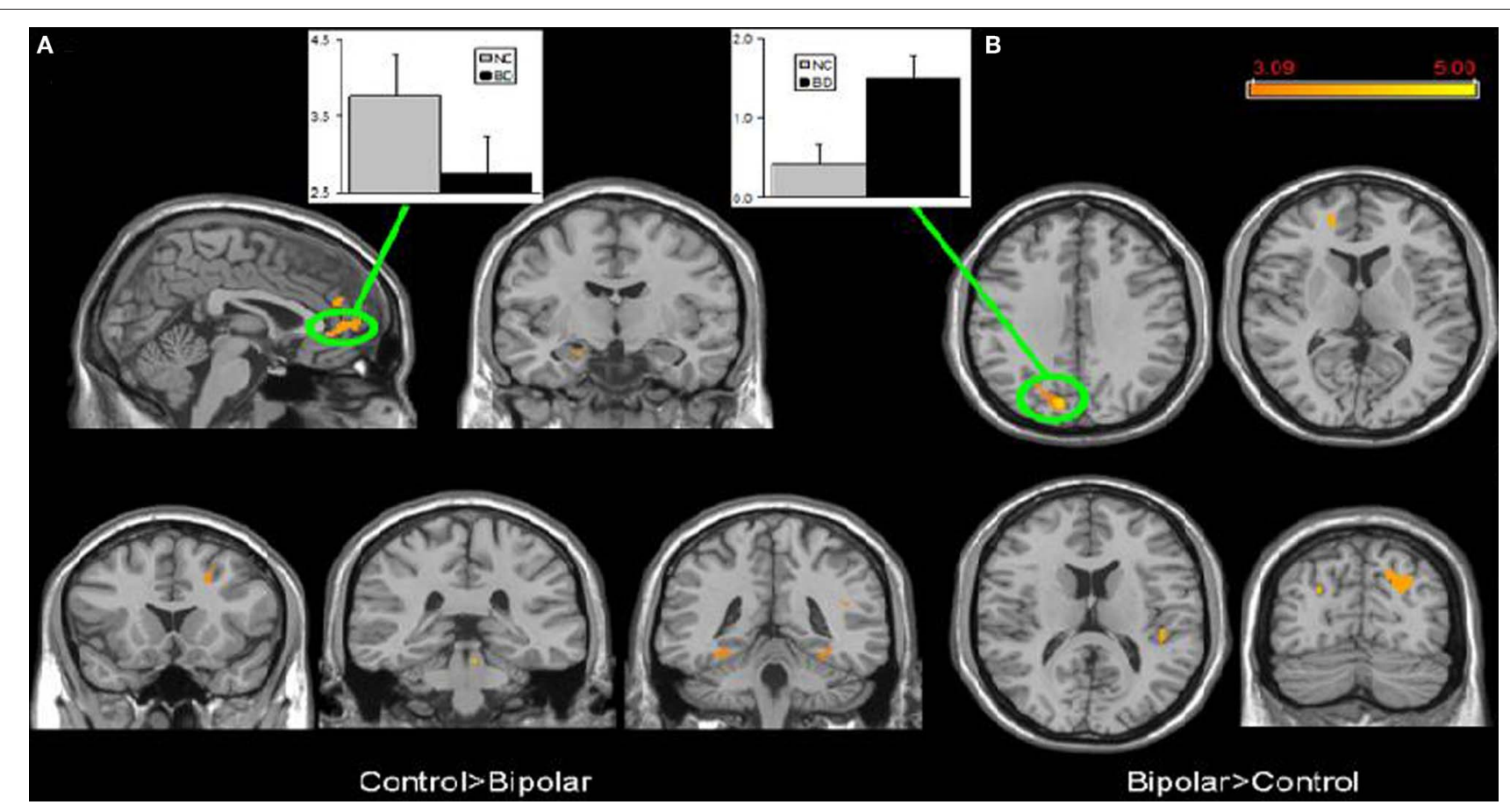

FIGURE 5 | Significant differences in the default mode network spatial extent between normal control and bipolar disorder subjects in whole brain analysis mapped onto parasagittal, coronal, and axial slices from a single subject's structural image in Talairach space; (A) Normal control > Bipolar disorder; (B) Bipolar disorder > Normal control. In each panel, average $z$-scores from a highlighted cluster are shown for normal control (gray) and bipolar disorder (black) groups, $p=0.001$, uncorrected; spatial extent $>25$ voxels. Reprinted from Öngür et al. (2010). Default mode network abnormalities in bipolar disorder and schizophrenia. Psychiatry Res. 183, 59-68 with permission from Elsevier. 


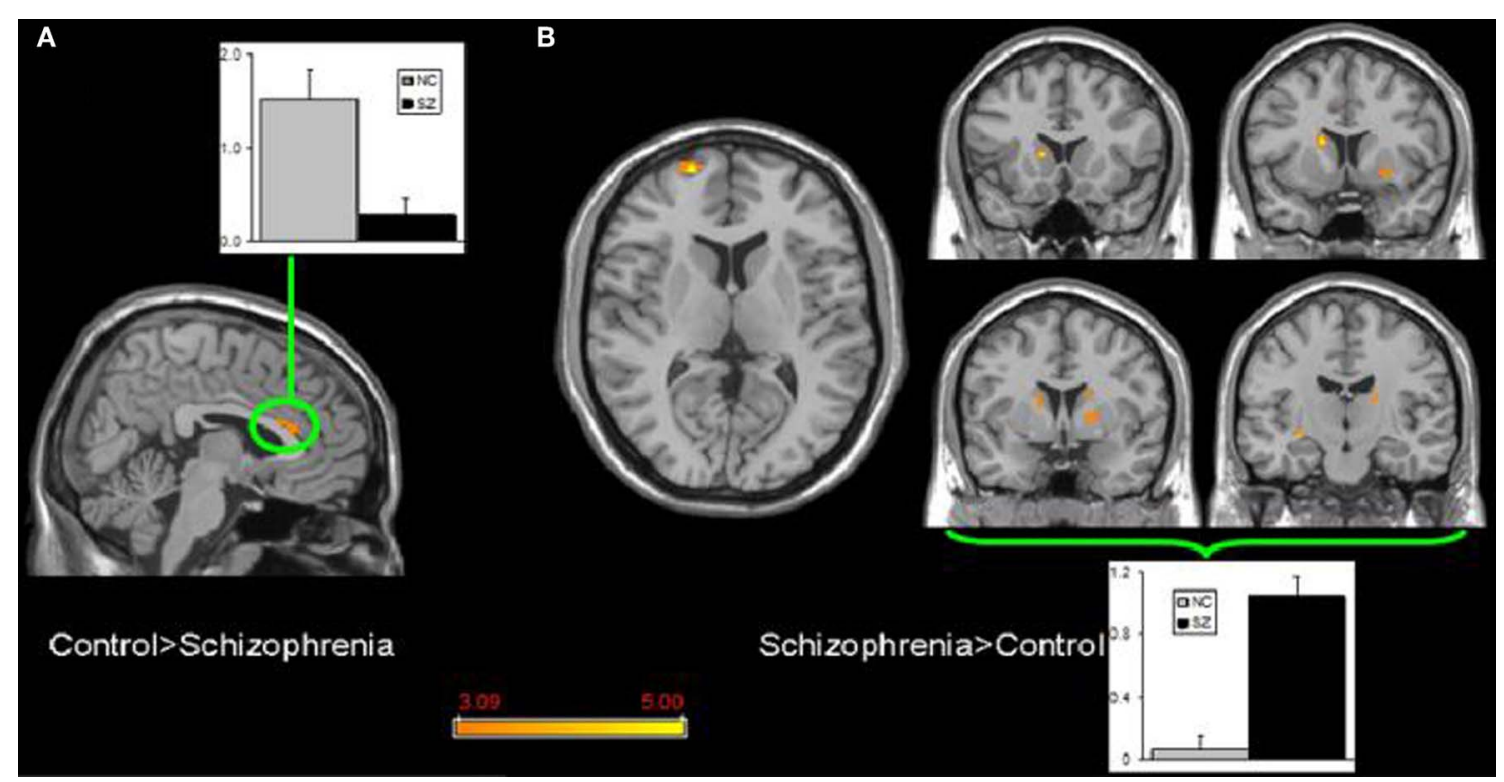

FIGURE 6 | Significant differences in the default mode network spatial extent between normal control and schizophrenia subjects in whole brain analysis mapped onto parasagittal, coronal, and axial slices from a single subject's structural image in Talairach space; (A) Normal control > Schizophrenia where the only finding is in the anterior cingulate cortexr; (B) Schizophrenia > Normal control where multiple clusters are seen throughout the basal ganglia. Average z-scores are shown for normal control (gray) and schizophrenia (black) groups from a highlighted cluster in (A), and from a group of clusters in the basal ganglia in (B). $p=0.001$, uncorrected; spatial extent $>25$ voxels. Reprinted from Öngür et al. (2010). Default mode network abnormalities in bipolar disorder and schizophrenia. Psychiatry Res. 183, 59-68 with permission from Elsevier.
The one thing that does not emerge from these studies is a prominent abnormality in the salience network in either schizophrenic or bipolar patients. There are differences in the insula but the insula is part of a wider network involved in awareness, not just salience, leading Williamson and Allman (2011) to include it as part of the representational brain network.

\section{NETWORK ANOMALIES UNDERLYING SCHIZOPHRENIA AND MOOD DISORDERS}

Although we have known for some time that schizophrenic patients demonstrate multiple deficits in various task-related networks, the characterization of the default mode network has provided a new way to evaluate abnormalities in internal thinking processes which are associated with this disorder. However, findings related to the default mode network in schizophrenia have been inconsistent. This is probably not surprising because the deficits demonstrated in task-related networks in schizophrenic patients are widespread and often contradictory as well (Williamson, 2006). The default mode network is very large and probably made up of as many complex networks as the task-related network.

The characterization of the salience network is an important step forward (Seeley et al., 2007). This network possibly provides a piece of the puzzle which was missing, that is, what modulates and controls the switch from the default network to the task-related network. It is reasonable to propose that this network along with the default mode network and task-related networks must be affected in many psychiatric disorders including schizophrenia (Menon, 2011; Palaniyappan and Liddle, 2012).
There is a rich pathophysiological literature implicating salience in schizophrenia (Kapur, 2003; Palaniyappan and Liddle, 2012). However, the question is whether these networks are sufficient to account for schizophrenia and other neuropsychiatric disorders? The structural and functional data reviewed above would suggest that they are not. The salience network does not emerge as being uniquely affected in schizophrenia nor do changes in these three networks separate schizophrenia from mood disorders.

The default mode network is highly adapted in the human brain and undergoes extensive development throughout the early years of life in concert with uniquely human capabilities such as theory of mind and language (Fair et al., 2007, 2008; Fransson et al., 2007; Rilling et al., 2007; Williamson and Allman, 2011). These specializations are possibly related to the abundance in humans of Von Economo neurons which are distributed throughout the dorsal and ventral ACC (ACC, see Figure 7, Allman et al., 2005). Dorsal-caudal locations of the anterior cingulate map onto frontoparietal attention networks while rostral-ventral locations map onto negatively correlated networks including the default mode network (Margulies et al., 2007). While the projections of Von Economo neurons are not yet known, it is highly likely that they project to the medial prefrontal cortex (frontal pole), a region known to be associated with information processing when more than one course of action may be required, such as representing the thoughts, actions, and feelings of others across time (Ramnani and Owen, 2004; Gilbert et al., 2006). Medial prefrontal regions and the right fronto-insula are less activated during social tasks in autism spectrum disorder patients (Di Martino et al., 2009). The ACC is also closely connected to the fronto-insula 


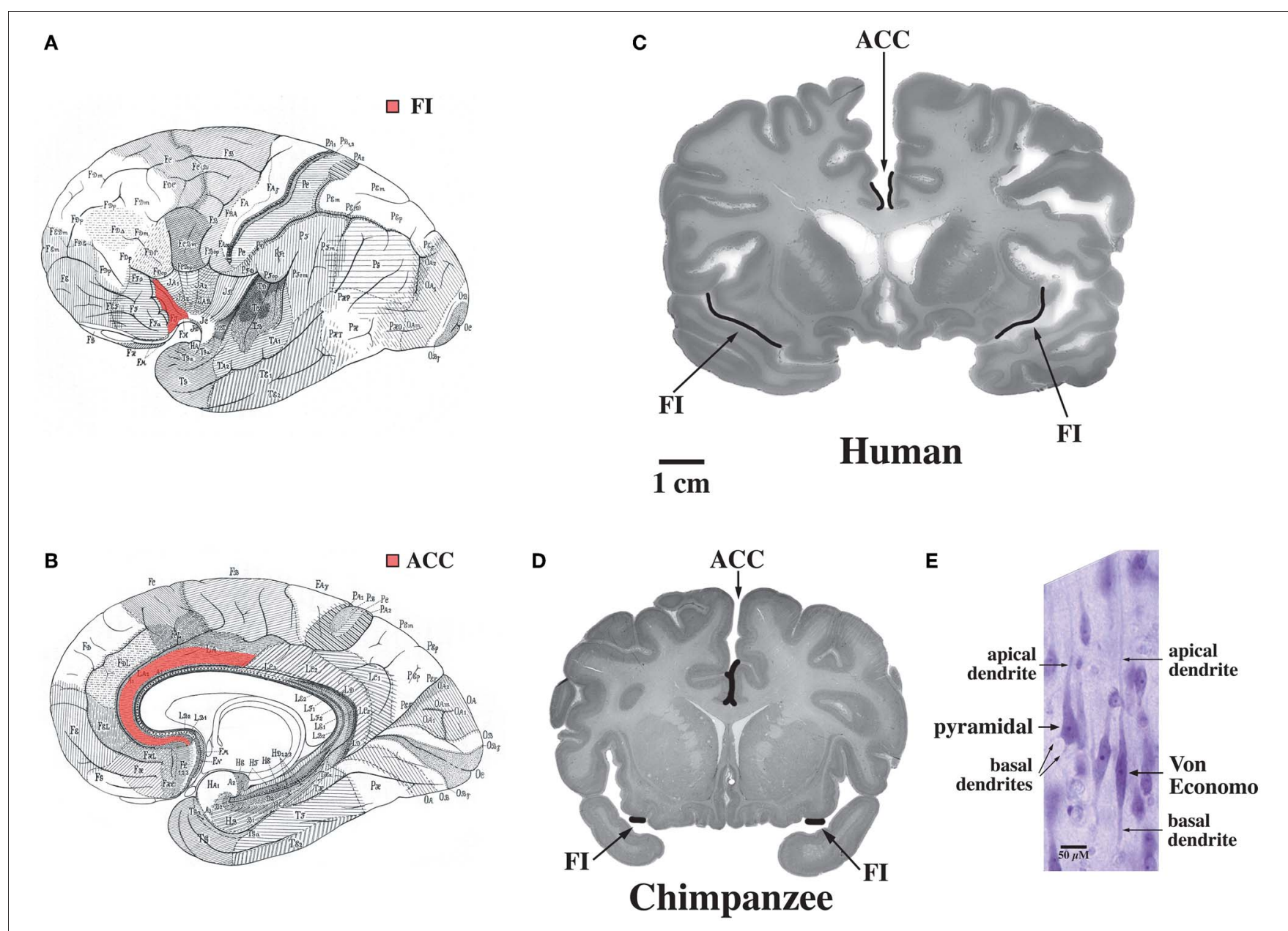

FIGURE 7 | Regions of the brain containing Von Economo neurons (VENs). (A) A lateral view of the brain, with fronto-insular cortex (FI) shown in red. (B) A medial view of the brain, with anterior cingulate cortex (ACC) shown in red. (C) FI and the spindle-cell-containing region of ACC indicated on coronal sections through a human brain (50-year-old female) and (D) a common chimpanzee brain (sections shown with the right hemisphere of the brain on the right of the figure). Note that $\mathrm{Fl}$ is much larger in the human than in the chimpanzee. (E) A Von Economo neuron and a pyramidal neuron in layer 5 of $\mathrm{FI}$. Both types of neuron have a single apical dendrite, but note that the VEN also has only a single basal dendrite, in contrast to the pyramidal neuron's multiple basal dendrites. Photomicrograph by the authors of a section from the 50-year-old human brain shown in part (C). Reprinted from Allman et al. Intuition and autism: a possible role for Von Economo neurons. Trends Cogn. Sci. 9, 367-373, Copyright 2005, with permission from Elsevier. which may be involved with social behaviors. In Williams syndrome patients, hypersocial behavior correlated with structural and functional imaging anomalies in the right anterior insula (Jabbi et al., 2012). Thus, the dorsal and ventral ACC are closely connected to regions involved in representing self and others. Could unique adaptions of the dorsal and ventral anterior cingulate possibly mediated by Von Economo neurons make the human brain vulnerable to schizophrenia and bipolar disorders?

The dorsal ACC has been implicated with the dorsolateral prefrontal cortex in the control of directed effort (Paus et al., 1998; Allman et al., 2001; Passingham et al., 2010). There is an extensive literature implicating functional, structural, and post-mortem anomalies in schizophrenic patients in these regions (Benes, 2000; Tamminga et al., 2000; Williamson, 2006; Williamson and Allman, 2011). Patients who damage this part of the brain are flat and amotivated (Damasio and Van Hoesen, 1983). The dorsal ACC and dorsolateral prefrontal cortex may also regulate cortical dopaminergic activity via projections to the brain stem (Lewis and González-Burgos, 2006). Never-treated, first episode schizophrenic patients have increased levels of glutamatergic metabolites in this region and the thalamus which decrease over time in association with gray matter loss and decline in social functioning (Bartha et al., 1997; Théberge et al., 2002; Aoyama et al., 2011). It is of note that schizophrenic patients given $\mathrm{N}$-methyl-D-aspartate antagonists show an increase in metabolism and glutamatergic metabolites in this region as well as an increase in symptoms (Lahti et al., 1995; Rowland et al., 2005).

The dorsal ACC is closely connected to speech processing regions anatomically and functionally in humans (Barbas et al., 1999; Hunter et al., 2006; Yukie and Shibata, 2009). It is also connected to the PCC and hippocampus. All of these regions have been associated with anomalies in schizophrenia. It is of note that these regions closely interact with basal ganglia-thalamocortical networks to effect action via glutamatergic cortical-subcortical 
pathways, which are regulated by dopamine, and are implicated in schizophrenia as well (Williamson, 2006). If the directed effort network fails to be fully engaged with the representational network then thoughts, feelings or actions may be perceived to belong to someone else. Thoughts may also be perceived as hallucinations and fear associated with these symptoms may lead to paranoia, all key symptoms of schizophrenia. The network depends on the coordinated activity of the dorsal ACC, PCC, auditory cortex and hippocampus so dysfunction at any of these nodes could disrupt the functioning of the network. Although there is preliminary evidence of decreased Von Economo neuron density in the anterior cingulate in early onset schizophrenia (Brüne et al., 2010), dysfunction would not necessarily be related to a loss of Von Economo neurons.

The ventral ACC is part of a network involved in emotional regulation including the orbitofrontal cortex, medial prefrontal cortex, and amygdala. Major depressive and bipolar disorders are clearly associated with anomalies in these regions. Histopathological, structural, and activation abnormalities during the presentation of emotional stimuli and reward paradigms have been reported in the posterior lateral and medial orbitofrontal cortex (Phillips et al., 2003; Drevets, 2007). Depression severity is inversely correlated with activity in these regions. Activity in the posterior ventral medial orbitofrontal cortex is increased in depression and decreased by antidepressant medications. Some parts of the orbitofrontal cortex inhibit while other regions facilitate emotional expression suggesting that the orbitofrontal cortex may be the ventral input to the representational brain (Drevets, 2007; Myers-Schulz and Koenigs, 2012). If emotional evaluative regions in the orbitofrontal cortex fail to engage with the representational network, enhanced output from posterior ventral medial structures could lead to changes

\section{REFERENCES}

Abe, O., Yamasue, H., Kasai, K., Yamada, H., Aoki, S., Inoue, H., Takei, K., Suga, M., Matsuo, K., Kato, T., Masutani, Y., and Ohtomo, K. (2010). Voxel-based analyses of gray/white matter volume and diffusion tensor data in major depression. Psychiatry Res. 181, 64-70.

Allman, J. M., Hakeem, A., Erwin, J. M., Nimchinsky, E., and Hof, P. (2001). The anterior cingulate cortex: the evolution of an interface between emotion and cognition. Ann. N.Y. Acad. Sci. 935, 107-117.

Allman, J. M., Watson, K. K., Tetreault, N. A., and Hakeem, A. Y. (2005). Intuition and autism: a possible role for Von Economo neurons. Trends Cogn. Sci. 9, 367-373.

Anand, A., Li, Y., Wang, Y., Lowe, M. J., and Dzemidzic, M. (2009). Resting state corticolimbic connectivity abnormalities in unmedicated bipolar disorder and unipolar depression. Psychiatry Res. 171, 189-198.
Aoyama, N., Théberge, J., Drost, D. J., Manchanda, R., Northcott, S., Neufeld, R. W. J., Menon, R. S., Rajakumar, N., Pavlosky, W. F., Densmore, M., Schaefer, B., and Williamson, P. C. (2011). Grey matter and social functioning correlates of glutamatergic metabolite loss in schizophrenia. Br. J. Psychiatry 198, 448-456.

Baiano, M., David, A., Versace, A., Churchill, R., Balestrieri, M., and Brambilla, P. (2007). Anterior cingulate volumes in schizophrenia: a systematic review and a metaanalysis of MRI studies. Schizophr. Res. 93, 1-12.

Barbas, H., Ghashghaei, H., Dombrowski, S. M., and RempelClower, N. L. (1999). Medial prefrontal cortices are unified by common connections with superior temporal cortices and distinguished by input from memory-related areas in the rhesus monkey. $J$. Comp. Neurol. 410, 343-367.

Bartha, R., Williamson, P. C., Drost, D. J., Malla, A., Carr, T. J., Cortese,

in the emotional response system mediated by the amygdala in depression while mania could result from decreased output from the posterior ventral medial prefrontal cortex to the amygdala or increased output to the amygdala from subgenual ventral medial prefrontal, positive emotion-enhancing regions (Myers-Schulz and Koenigs, 2012). Thus, depressed patients experience negative thoughts about themselves, the world, and the future as well as negative affect, distinguishing them from apparent depression in animals.

In the search for intrinsic brain networks which underlie schizophrenia and mood disorders, we suggest that it makes sense to think of distinct dorsal and ventral networks that interact with the representational networks and the dorsolateral prefrontal cortex (Williamson and Allman, 2011). In our view the suggestions of Buckner et al. (2008) and Northoff and Qin (2011) are consistent with this model. Both hypothesize aberrant coordination between the regions involved in mental simulation and auditory processing which may be mediated by the posterior cingulate. It should also be recognized that earlier models (Williamson, 2006), which integrate some of these regions, cannot be excluded at this point. Large-scale intrinsic network models are a work in progress but there is reason to believe that larger studies utilizing both structural and functional measurements may one day illuminate a neural basis for Kraepelin's astute clinical observations.

\section{ACKNOWLEDGMENTS}

This research was supported by the Tanna Schulich Chair in Neuroscience and Mental Health, the Canadian Institutes of Health Research, the Frank P. Hixon Chair of Neurobiology, the James S. McDonnell Foundation, the Simons Foundation, and the National Institutes of Mental Health.

L., Canaran MacFabe, G., Rylett, R. J., and Neufeld, R. W. J. (1997). Measurement of glutamate and glutamine in the medial prefrontal cortex of never-treated schizophrenic patients and healthy controls using proton magnetic resonance spectroscopy. Arch. Gen. Psychiatry 54, 959-965.

Benedetti, F., Yeh, P.-H., Bellani, M. Radaelli, D., Nicoletti, M. A. Poletti, S., Falini, A., Dallaspezia, S., Colomo, C., Scotti, G., Smeraldi, E., Soares, J. C., and Brambilla, P. (2011). Disruption of white matter integrity in bipolar depression as a possible structural marker of illness. Biol. Psychiatry 69, 309-317.

Benes, F. M. (2000). Emerging principles of altered neural circuitry in schizophrenia. Brain Res. Brain Res. Rev. 31, 251-269.

Berman, M. G., Peltier, S., Nee, D. E., Kross, E., Deldin, P. J., and Jonides, J. (2011). Depression, rumination and the default network. Soc. Cogn. Affect. Neurosci. 6, 548-555.
Bluhm, R., Miller, J., Lanius, R. A. Osuch, E. A., Boksman, K., Neufeld, R. W. J., Théberge, J., Schaefer, B., and Williamson, P. C. (2007). Sponanteous low-frequency fluctuations in the BOLD signal in schizophrenia patients: anomalies in the default network. Schizophr. Bull. 33, 1004-1012.

Bluhm, R. L., Miller, J., Lanius, R. A., Osuch, E. A., Boksman, K., Neufeld, R. W. J., Théberge, J., Schaefer, B., and Williamson, P. C. (2009a). Retrosplenial cortex connectivity in schizophrenia. Psychiatry Res. 174, 17-23.

Bluhm, R., Williamson, P. C., Lanius, R. A., Théberge, J., Densmore, M., Bartha, R., Neufeld, R., and Osuch, E. (2009b). Resting state default-mode network connectivity in early depression using a seed region-of-interest analysis: decreased connectivity with caudate nucleus. Psychiatry Clin. Neurosci. 63, 754-761.

Bora, E., Fornito, A., Radua, J., Walterfang, M., Seal, M., Wood, 
S. J., Yücel, M., Velakoulis, D., and Pantelis, C. (2011). Neuroanatomical abnormalities in schizophrenia: a multimodal voxelwise meta-analysis and metaregression analysis. Schizophr. Res. $127,46-57$.

Bora, E., Fornito, A., Yücel, A., and Pantelis, C. (2010). Voxelwise meta-analysis of gray matter abnormalities in bipolar disorder. Biol. Psychiatry 67, 1097-1105.

Broyd, S. J., Demanuele, C., Debener, S., Helps, S. K., James, C. J., and Sonuga-Barke, E. J. S. (2009). Default-mode brain dysfunction in mental disorders: a systematic review. Neurosci. Biobehav. Rev. 33 , 279-296.

Brüne, M., Schöbel, A., Karau, R., Benali, A., Faustmann, P. M., Juckel, J., and Petrasch-Parwez, E. (2010). Von Economo neuron density in the anterior cingulate cortex is reduced in early onset schizophrenia. Acta Neuropathol. 119, 771-778.

Buckner, R. L., Andrews-Hanna, J. R., and Schacter, D. L. (2008). The brain's default network. Anatomy, function and relevance to disease. Ann. N.Y. Acad. Sci. 1124, 1-38.

Calhoun, V. D., Eichele, T., and Pearlson, G. (2009). Functional brain networks in schizophrenia: a review. Front. Hum. Neurosci. 3:17. doi: 10.3389/neuro.09.017.2009

Calhoun, V., Kiehl, K. A., and Pearlson, G. D. (2008). Modulation of temporally coherent brain networks estimated using ICA at rest and during cognitive tasks. Hum. Brain Mapp. 29, 828-838.

Calhoun, V., Maciejewski, P. K., Pearlson, G. D., and Kiehl, K. A. (2008). Temporal lobe and "default" hemodynamic brain modes discriminate between schizophrenia and bipolar disorder. Hum. Brain Mapp. 29, 1265-1275.

Calhoun, V. D., Sui, J., Kiehl, K., Turner, J., Allen, E., and Pearlson, G. (2012). Exploring the psychosis functional connectome: aberrant intrinsic networks in schizophrenia and bipolar disorder. Front. Psychiatry 2:75. doi: 10.3389/fpsyt.2011.00075

Campbell, S., Marriott, M., Nahmias, C., and MacQueen, G. M. (2004). Lower hippocampal volume in patients suffering from depression: a meta-analysis. Am. J. Psychiatry 161, 598-607.

Chai, X. J., Whitfield-Gabrieli, S., Shinn, A. K., Gabrielli, J. D. E., Castañón, A. N., McCarthy, J. M., Cohen, B. M., and Öngür, D. (2011). Abnormal medial prefrontal cortex resting-state connectivity in bipolar disorder and schizophrenia. Neuropsychopharmacology 36, 2009-2017.

Chepenik, L. G., Raffo, M., Hampson, M., Lacadie, C., Wang, F., Jones, M. M., Pittman, B., Skudlarski, P., and Blumberg, H. P. (2010). Functional connectivity between ventral prefrontal cortex and amygdala at low frequency in the resting state in bipolar disorder. Psychiatry Res. 182, 207-210.

Cheung, V., Cheung, C., McAlonan, G. M., Deng, Y., Wong, J. G., Yip, L., Tai, K. S., Khong, P. L., Sham, P., and Chua, S. E. (2008). A diffusion tensor imaging study of structural dysconnectivity in never-medicated, first-episode schizophrenia. Psychol. Med. 38, 877-885.

Craddock, N., and Owen, M. J. (2010). The Kraepelinian dichotomy: going, going ...but still not gone. Br. J. Psychiatry 196, 92-95.

Craig, A. D. (2009). How do you feel-now? The anterior insula and human awareness. Nat. Rev. Neurosci. 10, 59-70.

Cullen, K. R., Gee, D. G., KlimesDougan, B., Gabbay, V., Hulvershorn, L., Mueller, B. A., Camchong, J., Bell, C. J., Houri, A., Kumra, S., Lim, K. O., Castellanos, F. X., and Milham, M. P. (2009). A preliminary study of functional connectivity in comorbid adolescent depression. Neurosci. Lett. 460, 227-231.

Cullen, K. R., Klimes-Dougan, B., Muetzel, R., Mueller, B., Camchong, J., Houri, A., Kurma, S., and Lim, K. O. (2010). Altered white matter microstructure in adolescents with major depression: a preliminary study. J. Am. Acad. Child Adolesc. Psychiatry 49, 173-183.

Damasio, H., Tranel, D., Grabowski, T., Adolphs, R., and Damasio, A. (2004). Neural systems behind word and concept retrieval. Cognition 92, 179-229.

Damasio, A. R., and Van Hoesen, G. W. (1983). "Focal lesions of the limbic frontal lobe," in Neuropsychology of Human Emotion, eds K. M. Heilman and P. Satz (New York, NY: Guilford Press), 85-110.

DeLisi, L. E. (2008). The concept of progressive brain changes in schizophrenia: implications for understanding schizophrenia. Schizophr. Bull. 34, 312-321.

De Luca, M., Beckmann, C. F., De Stefano, N., Matthews, P. M., and Smith, S. M. (2006). fMRI resting state networks define distinct modes of long-distance interactions in the human brain. Neuroimage 29, 1359-1367.
Dickstein, D. P., Gorrostieta, C. Ombao, H., Goldberg, L. D., Brazel, A. C., Gable, C. J., Kelly, C., Gee, D. G., Zuo, X.-N., Castellanos, F. X., and Milham, M. P. (2010). Frontotemporal spontaneous resting state functional connectivity in pediatric bipolar disorder. Biol. Psychiatry 68, 839-846.

Di Martino, A., Ross, K., Uddin L. Q., Sklar, A. B., Castellanos, X., and Milham, M. P. (2009). Functional brain correlates of social and nonsocial processes in autism spectrum disorders: an activation likelihood estimation meta-analysis. Biol. Psychiatry 65, 63-74.

Drevets, W. C. (2007). Orbitofrontal cortex function and structure in depression. Ann. N.Y. Acad. Sci. 1121, 499-527.

Ellison-Wright, I., and Bullmore, E. (2009). Meta-analysis of diffusion tensor imaging studies in schizophrenia. Schizophr. Res. 108, 3-10.

Ellison-Wright, I., and Bullmore, E. (2010). Anatomy of bipolar disorder and schizophrenia: a meta-analysis. Schizophr. Res. 117, 1-12.

Ellison-Wright, I., Glahn, D. C., Laird, A. R., Thelen, S. M., and Bullmore, E. (2008). The anatomy of firstepisode and chronic schizophrenia: an anatomical likelihood estimation meta-analysis. Am. J. Psychiatry 165, 1015-1023.

Fair, D. A., Cohen, A. L., Dosenbach, N. U. F., Church, J. A., Miezin, F. M., Barch, D. M., Raichle, M. E. Peterson, S. E., and Schlaggar, B. L. (2008). The maturing architecture of the brain's default network Proc. Natl. Acad. Sci. U.S.A. 105, 4018-4032.

Fair, D. A., Dosenbach, N. U. F., Church, J. A., Cohen, A. L., Brahmbhatt, S., Miezin, F. M., Barch, D. M., Raichle, M. E. Petersen, S. E., and Schlaggar, B. L. (2007). Development of distinct control network through segregation and integration. Proc. Natl. Acad. Sci. U.S.A.104, 13507-13512.

Fox, M. D., Snyder, A. Z., Vincent, J. L., Corbetta, M., Van Essen, D. C., and Raichle, M. E. (2005). The human brain is intrinsically organized into dynamic, anticorrelated functional networks. Proc. Natl. Acad. Sci. U.S.A. 102, 9673-9678.

Fransson, P. (2005). Spontaneous lowfrequency BOLD signal fluctuations: an fMRI investigation of resting-state default mode of brain function hypothesis. Hum. Brain Mapp. 26, 15-29.

Fransson, P., Skiöld, B., Horsch, S., Nordell, A., Blennow, M.
Lagercrantz, H., and Aden, U. (2007). Resting-state networks in the infant brain. Proc. Natl. Acad. Sci. U.S.A. 104, 15531-15536.

Fornito, A., Yücel, M., Dean, B., Wood, S. J., and Pantelis, C. (2009a). Anatomical abnormalities of the anterior cingulate cortex in schizophrenia: bridging the gap between neuroimaging and neuropathology. Schizophr. Bull. 35, 973-993.

Fornito, A., Yücel, M., Patti, J., Wood, S. J., and Pantelis, C. (2009b). Mapping grey matter reductions in schizophrenia: an anatomical likelihood estimation analysis of voxel-based morphometry studies. Schizophr. Res. 108, 104-113.

Frith, C. D. (2007). The social brain? Philos. Trans. R. Soc. Lond. B Biol. Sci. 362, 671-678.

Garrity, A. G., Pearlson, G. D., McKiernan, K., Lloyd, D., Kiehl, K. A., and Calhoun, V. D. (2007) Aberrant "default mode" functional connectivity in schizophrenia. Am. J. Psychiatry 164, 450-457.

Gilbert, S. J., Spengler, S., Simons, J. S., Steele, J. D., Lawrie, S. M., Frith, C. D., and Burgess, P. W. (2006). Functional specialization within rostral prefrontal cortex (area 10): a meta-analysis. J. Cogn. Neurosci. 18, 932-948.

Glahn, D. C., Laird, A. R., EllisonWright, I., Thelen, S. M., Robinson, J. L., Lancaster, J. L., Bullmore, E., and Fox, P. T. (2008). Metaanalysis of gray matter anomalies in schizophrenia: application of anatomic likelihood estimation and network analysis. Biol. Psychiatry 64, 774-781.

Gogtay, N., Sporn, A., Clasen, L. S., Nugent, T. F., Greenstein, D., Nicolson, R., Giedd, J. N., Lenane, M., Gochman, P., Evans, A., and Rapaport, J. L. (2004). Comparison of progressive cortical gray matter loss in childhood-onset schizophrenia with that in childhood-onset atypical psychoses. Arch. Gen Psychiatry 61, 17-22.

Goodwin, F. K., and Jamison, K. R. (2007). Manic-depressive Illness: Bipolar Disorders and Recurrent Depression. New York, NY: Oxford University Press.

Greicius, M. (2008). Resting-state functional connectivity in neuropsychiatric disorders. Curr. Opin. Neurol. 21, 424-430

Greicius, M. D., Flores, B. H., Menon, V., Glover, G. H., Solvason, H. B., Kenna, H., Reiss, A. L., and Schatzberg, A. F. (2007). Restingstate functional connectivity in major depression: abnormally 
increased contributions from subgenual cingulate cortex and thalamus. Biol. Psychiatry 62, 429-437.

Grimm, S., Boesiger, P., Beck, J., Schuepbach, D., Bermpohl, F., Walter, M., Ernst, J., Hell, D., Boeker, H., and Northoff, G. (2009). Altered negative BOLD responses in the default-mode network during emotion processing in depressed subjects. Neuropsychopharmacology 34, 932-943.

Grimm, S., Ernst, J., Boesiger, P., Schuepbach, D., Boeker, H., and Northoff, G. (2011). Reduced negative BOLD responses in the default-mode network and increased self-focus in depression. World J. Biol. Psychiatry 12, 627-637.

Haldane, M., and Frangou, S. (2004). New insights help define the pathophysiology of bipolar affective disorder: neuroimaging and neuropathology findings. Prog. Neuropsychopharmacol. Biol. Psychiatry 28, 943-960.

Hamilton, J. P., Furman, D. J., Chang, C., Thomason, M. E., Dennis, E., and Gotlib, I. H. (2011). Defaultmode and task-positive network activity in major depressive disorder: implications for adaptive and maladaptive rumination. Biol. Psychiatry 70, 327-333.

Hajek, T., Kozeny, J., Kopecek, M., Alda, M., and Höschl, C. (2008). Reduced subgenual cingulate volumes in mood disorders: a metaanalysis. J. Psychiatry Neurosci. 33, 91-99.

Hasenkamp, W., James, G. A., Boshoven, W., and Duncan, E. (2011). Altered engagement of attention and default networks during target detection in schizophrenia. Schizophr. Res. 125, 169-173.

Hasler, G., and Northoff, G. (2011). Discovering imaging endophenotypes for major depression. Mol. Psychiatry 16, 604-619.

Honea, R., Crow, T., Passingham, D., and Mackay, C. E. (2005). Regional deficits in brain volume in schizophrenia: a meta-analysis of voxel-based morphometry studies. Am. J. Psychiatry 162, 2233-2245.

Ho, B. C., Andreasen, N. C., Ziebell, S., Pierson, R., and Magnotta, V. (2011). Long-term antipsychotic treatment and brain volumes. Arch. Gen. Psychiatry 68, 128-137.

Hoptman, M. J., Zuo, X.-N., Butler, P. D., Javitt, D. C., D’Angelo, D., Mauro, C. J., and Milham, M. P. (2010). Amplitude of low-frequency oscillations in schizophrenia: a resting state fMRI study. Schizophr. Res. 117, 13-20.

Huang, X.-Q., Lui, S., Deng, W., Chan, R. C. K., Wu, Q.-Z., Jiang, L.-J., Zhang, J.-R., Jia, Z.-Y., Li, X.-L., Li, F., Chen, L., Li, T., and Gong, Q.-Y. (2010). Localization of cerebral functional deficts in treatment-naïve, first-episode schizophrenia using resting-state fMRI. Neuroimage 49, 2901-2906.

Hunter, M. D., Eickhoff, S. B., Miller, T. W. R., Farrow, T. F. D., Wilkinson, I. D., and Woodruff, P. W. R. (2006). Neural activity in speech-sensitive auditory cortex during silence. Proc. Natl. Acad. Sci. U.S.A. 103, 189-194. Jabbi, M., Kippenhan, J. S., Kohn, P., Marenco, S., Mervis, C. B., Morris, C. A., Meyer-Lindenberg, A., and Berman, K. F. (2012). The Williams syndrome chromosome 7q11.23 hemideletion confers hypersocial, anxious personality coupled with altered insula structure and function. Proc. Natl. Acad. Sci. U.S.A. Published online March 12, 2012. doi: 10.1073/pnas. 1114774109

Jafri, M. J., Pearlson, G. D., Stevens, M., and Calhoun, V. D. (2008). A method for functional network connectivity among spatially independent resting-state components in schizophrenia. Neuroimage 39, 1666-1681.

Jang, J. H., Jung, W. H., Choi, J.S., Choi, C.-H., Kang, D.-H., Shin, N. Y., Hong, K. S., and Kwon, J. S. (2011). Reduced prefrontal functional connectivity in the default mode network is related to greater psychopathology in subjects with high genetic loading in schizophrenia. Schizophr. Res. 127, 58-65.

Jann, K., Dierks, T., Boesch, C., Kottlow, M., Strik, W., and Koenig, T. (2009). BOLD correlates of EEG alpha phase-locking and the fMRI default mode network. Neuroimage 35, 903-916.

Kanaan, R. A., Kim, J.-S., Kaufmann, W. E., Pearlson, G. D., Barker, G. J., and McGuire, P. K. (2005). Diffusion tensor imaging in schizophrenia. Biol. Psychiatry 58, 921-929.

Kapur, S. (2003). Psychosis as a state of aberrant salience: a framework linking biology, phenomenology, and pharmacology in schizophrenia. Am. J. Psychiatry 160, 13-23.

Ke, M., Zou, R., Shen, H., Huang, X., Zhou, Z., Liu, Z., Xue, Z., and $\mathrm{Hu}$, D. (2010). Bilateral functional asymmetry disparity in positive and negative schizophrenia revealed by resting-state fMRI. Psychiatry Res. $182,30-39$.
Kim, D. I., Manoach, D. S., Mathalon, D. H., Turner, J. A., Mannell, M. Brown, G. G., Ford, J. M., Gollub, R. L., White, T., Wible, C., Belger, A., Bockholt, H. J., Clark, V. P. Lauriello, J., O’Leary, D., Mueller, B. A., Lim, K. O., Andreasen, N. Potkin, S. G., and Calhoun, V. D. (2009). Dysregulation of working memory and default-mode networks in schizophrenia using independent component analysis, an fBIRN and MCIC study. Hum. Brain Mapp. 30, 3795-3811.

Korgaonkar, M. S., Grieve, S. M., Koslow, S. H., Gabrieli, J. D. E., Gordon, E., and Williams, L. M. (2011). Loss of white matter integrity in major depressive disorder: evidence using tract-based spatial statistical analysis of diffusion tensor imaging. Hum. Brain Mapp. 32, 2161-2171.

Kubicki, M., McCarley, R., Westin, C. F., Park, H.-P., Maier, S., Kikinis, R., Jolesz, F. A., and Shenton, M. E. (2007). A review of diffusion tensor imaging studies in schizophrenia. J. Psychiatr. Res. 41, 15-30.

Kyriakopoulis, M., Bargiotas, T., Barker, G. J., and Frangou, S. (2008). Diffusion tensor imaging in schizophrenia. Eur. Psychiatry 23, 255-273.

Lahti, A. C., Koffe, 1. B., Laporte, D., and Tamminga, C. A. (1995). Subanesthetic doses of ketamine stimulate psychosis in schizophrenia. Neuropsyhopharmacology 13 , 9-19.

Lee, K., Yoshida, T., Kubicki, M. Bouix, S., Westin, C.-F., Kindlmann, G., Niznikiewicz, M., Cohen, A. McCarley, R. W., and Shenton, M. E. (2009). Increased diffusivity in superior temporal gyrus in patients with schizophrenia: a diffusion tensor imaging study. Schizophr. Res. $108,33-40$.

Lewis, D. A., and González-Burgos, G. (2006). Pathophysiologically based treatment interventions in schizophrenia. Nat. Med. 12, 1016-1022.

Li, L., Ma, N., Li, Z., Tan, L., Liu, J., Gong, G., Shu, N., He, Z., Jiang, T., and $\mathrm{Xu}, \mathrm{L}$. (2007). Prefrontal white matter abnormalities in young adult with major depressive disorder: a diffusion tensor imaging study. Brain Res. 1168, 124-128.

Lichtenstein, P., Yip, B. H., Björk, C., Pawitan, Y., Cannon, T. D., Sullivan, P. F., and Hultman, C. M (2009). Common genetic determinants of schizophrenia and bipolar disorder in Swedish families: a population-based study. Lancet 373 , 234-239.
Liemburg, E. J., Vercammen, A., Ter Horst, G. J., Curcic-Blake, B., Knegtering, H., and Aleman, A. (2012). Abnormal connectivity between attention, language and auditory networks in schizophrenia. Schizophr. Res. 135, 15-22.

Lui, S., Li, T., Deng, W., Jiang, L., Wu, Q., Tang, H., Yue, Q., Huang, X., Chan, R. C., Collier, D. A., Meda, S. A., Pearlson, G., Mechelli, A., Sweeney, J. A., and Gong, Q. (2010). Short-term effects on antipsychotic treatment on cerebral function in drug-naïve first-episode schizophrenia revealed by "resting state" functional magnetic resonance imaging. Arch. Gen. Psychiatry 67, 783-792.

Lynall, M.-E., Bassett, D. S., Kerwin, R., McKenna, P. J., Kitzbichler, M., Muller, U., and Bullmore, E. (2010). Functional connectivity and brain networks in schizophrenia. J. Neurosci. 30, 9477-9487.

Ma, L., Li, L., Shu, N., Liu, J., Gong, G., He, Z., Li, Z., Tan, L., Stone, W. S., Zhang, Z., Xu, L., and Jiang, T. (2007). White matter abnormalities in first-episode, treatment-naïve young adults with major depressive disorder. Am. J. Psychiatry 164, 823-826.

Mannell, M. V., Franco, A. R., Calhoun, V. D., Caňive, J. M., Thoma, R. J., and Mayer, A. R. (2010). Resting state and task-induced deactivation: a methodological comparison in patients with schizophrenia and healthy controls. Hum. Brain Mapp. 31, 424-437.

Margulies, D. S., Kelly, A. M. C., Uddin, L. Q., Biswal, B. B., Castellanos, F. X., and Milham, M. P. (2007). Mapping the functional connectivity of the anterior cingulate cortex. Neuroimage 37, 579-588.

Mayberg, H. S., Liotti, M., Brannan, S. K., McGinnis, S., Mahurin, R. K. Jerabek, P. A., Silva, J. A., Tekell, J. L., Martin, C. C., Lancaster, J. L., and Fox, P. T. (1999). Reciprocal limbic-cortical function and negative mood: converging PET findings in depression and normal sadness. Am. J. Psychiatry 156, 675-682.

McCabe, C., Mishor, Z., Filippini, N., Cowen, P. J., Taylor, M. J., and Harmer, C. J. (2011). SSRI administration reduces resting state functional connectivity in dorso-medial prefrontal cortex. Mol. Psychiatry $16,592-594$.

McDonald, C., Zanelli, J., RabeHesketh, S., Ellison-Wright, I., Sham, P., Kalidindi, S., Murray, R. M., and Kennedy, N. (2004). Meta-analysis of magnetic resonance imaging brain morphometry 
studies in bipolar disorder. Biol. Psychiatry 56, 411-417.

Menon, V. (2011). Large-scale brain networks and psychopathology: a unifying triple network model. Trends Cogn. Sci. 15, 483-506.

Mori, T., Ohnishi, T., Hashimoto, R., Nemoto, K., Moriguchi, Y., Noguchi, H., Nakabayashi, T., Hori, H., Harada, S., Saitoh, O., Matsuda, H., and Kunugi, H. (2007). Progressive changes of white matter integrity in schizophrenia revealed by diffusion tensor imaging. Psychiatry Res. 154, 133-145.

Myers-Schulz, B., and Koenigs, M. (2012). Functional anatomy of ventromedial prefrontal cortex: implications for mood and anxiety disorders. Mol. Psychiatry 17, 132-141.

Nakamura, M., Salisbury, D. F., Hirayasu, Y., Bouix, S., Pohl, K. M., Yoshida, T. K. M.-S., Shenton, M. E., and McCarley, R. W. (2007). Neocortical gray matter volume in first-episode schizophrenia and first-episode affective psychosis: a cross-sectional and longitudinal MRI study. Biol. Psychiatry 62, 773-783.

Navani, S., and Dazzan, P. (2008). Do antipsychotic drugs affect brain structure? A systematic and critical review of MRI findings. Psychol. Med. 39, 1763-1777.

Northoff, G., and Qin, P. (2011). How can the brain's resting state activity generate hallucinations? A "resting state hypothesis" of auditory verbal hallucinations. Schizophr. Res. 127, 202-214.

Northoff, G., Wiebking, C., Feinberg, T., and Panksepp, J. (2011). The "resting-state hypothesis" of major depressive disorder- a translational subcortical-cortical framework for a system disorder. Neurosci. Biobehav. Rev. 35, 1929-1945.

Olabi, B., Ellison-Wright, I., McIntosh, A. M., Wood, S. J., Bullmore, E., and Lawrie, S. M. (2011). Are there progressive brain changes in Schizophrenia? A meta-analysis of structural magnetic resonance imaging studies. Biol. Psychiatry 70, 88-96.

Öngür, D., Lundy, M., Greenhouse, I., Shinn, A. K., Menon, V., Cohen, B. M., and Renshaw, P. F. (2010). Default mode network abnormalities in bipolar disorder and schizophrenia. Psychiatry Res. 183, 59-68.

Palaniyappan, L., and Liddle, P. F. (2012). Does the salience network play a cardinal role in psychosis? An emerging hypothesis of insular dysfunction. J. Psychiatry Neurosci. 37, 17-27.

Park, I. H., Kim, J.-J., Chun, J., Jung, Y. C., Seok, J. H., Pakr, H.-J., and Lee, J. D. (2009). Medial prefrontal default-mode hypoactivity affecting trait physical anhedonia in schizophrenia. Psychiatry Res. 171, 155-165.

Passingham, R. E., Bengtsson, S. L., and Lau, H. C. (2010). Medial frontal cortex: from self-generated action to reflection on one's own performance. Trends Cogn. Sci. 14, 16-21.

Patel, S., Mahon, K., Wellington, R., Zhang, J., Chaplin, W., and Szeszko, P. R. (2011). A meta-analysis of diffusion tensor imaging studies of the corpus callosum in schizophrenia. Schizophr. Res. 129, 149-155.

Paus, T., Koski, L., Caramanos, Z., and Westbury, C. (1998). Regional differences in the effects of task difficulty and motor output on blood flow response in the human anterior cingulate cortex: a review of 107 PET activation studies. Neuroreport 9, R37-R47.

Peng, D.-H., Jiang, K.-D., Fang, Y.R., Xu, Y.-F., Shen, T., Long, X.Y., Liu, J., and Zang, Y.-F. (2011). Decreased regional homogeneity in major depression as revealed by resting-state functional magnetic resonance imaging. Chin. Med. J. 124, 369-373.

Phillips, M. L., Drevets, W. C., Rauch, S. L., and Lane, R. (2003). Neurobiology of emotion perception II: implications for major psychiatric disorders. Biol. Psychiatry 54, 515-528.

Pomarol-Clotet, E., CanalesRodriguez, E. J., Salvador, R., Sarró, S., Gomar, J. J., Vila, F., Ortiz-Gil, J., Iturria-Medina, Y., Capdevila, A., and McKenna, P. J. (2010). Medial prefrontal cortex pathology in schizophrenia as revealed by convergent findings from multimodal imaging. Mol. Psychiatry 15, 823-830.

Pomarol-Clotet, E., Salvador, R., Sarró, S., Gomar, J., Vila, F., Martinez, Á., Guerrero, A., Ortiz-Gil, J., Sans-Sansa, B., Capdevila, A., Cebamanos, J. M., and Mckenna, P. J. (2008). Failure to deactivate in the prefrontal cortex in schizophrenia: dysfunction of the default mode network? Psychol. Med. 38, 1185-1193.

Ramnani, N., and Owen, A. M. (2004). Anterior prefrontal cortex: insights into function from anatomy and neuroimaging. Nat. Rev. Neurosci. 4, 184-194.

Repovs, G., Csernansky, J. G., and Barch, D. M. (2011). Brain network connectivity in individuals with schizophrenia and their siblings. Biol. Psychiatry 69, 967-973.

Rilling, J. K., Barks, S. K., Parr, L. A., Preuss, T. M., Faber, T. L., Pagnoni, G., Bremner, J. D., and Votaw, J. R. (2007). A comparison of restingstate brain activity in humans and chimpanzees. Proc. Natl. Acad. Sci. U.S.A. 104, 17146-17151.

Rotarska-Jagiela, A., Oertel-Knoechel, V., DeMartino, F., van de Ven, V., Formisano, E., Roebroeck, A., Rami, A., Schoenmeyer, R., Haenschel, C. Hendler, T., Maurer, K., Vogeley, K., and Linden, D. E. (2009) Anatomical brain connectivity and positive symptoms of schizophrenia: a diffusion tensor imaging study. Psychiatry Res. 174, 9-16.

Rotarska-Jagiela, A., van de Ven, V. Oertel-Knöchel, V., Uhlhaas, P. J. Vogeley, K., and Linden, D. E. J. (2010). Resting-state functional network correlates of psychotic symptoms in schizophrenia. Schizophr. Res. 117, 21-30.

Rowland, L. M., Bustillo, J. R., Mullins, P. G., Jung, R. E., Lenroot, R. Landgraf, E., Barrow, R., Yeo, R., Lauriello, J., and Brooks, W. M. (2005). Effects of ketamine on AC glutamate metabolism in healthy humans: a 4-T proton MRS study. Am. J. Psychiatry 162, 394-396.

Salgado-Pineda, P., Fakra, E., Delaveau, P., McKenna, P. J., Pomarol-Clotet, E., and Blin, O. (2011). Correlated structural and functional abnormalities in the default mode network in schizophrenia. Schizophr. Res. 125 101-109.

Sambataro, F., Blasi, G., Fazio, L., Caforio, G., Taurisano, P., Romano, R., Di Giorgio, A., Gelao, B., Lo Bianco, L., Papazacharias, A., Popolizio, T., Nardini, M., and Bertolino, A. (2010). Treatment with olanzapine is associated with modulation of the default mode network in patients with schizophrenia. Neuropsychopharmacology 35, 904-912.

Savitz, J., and Drevets, W. C. (2009). Bipolar and major depressive disorder: neuroimaging the developmental-degenerative divide. Neurosci. Biobehav. Rev. 33 699-771.

Schneider, F. C., Royer, A., Grosselin, A., Pellet, J., Barral, F.-G., Laurent, B., Brouillet, D., and Lang, F. (2011). Modulation of the default mode network is task-dependant in chronic schizophrenia patients. Schizophr. Res. 125, 110-117.

Seeley, W. W., Menon, V., Schatzberg, A. F., Keller, J., Glover, G. H.
Kenna, H., Reiss, A. L., and Greicius, M. D. (2007). Dissociable intrinsic connectivity networks for salience processing and executive control. J. Neurosci. 27, 2349-2356.

Segall, J. M., Turner, J. A., van Erp, T. G. M., White, T., Bockholt, H. J., Gollub, R. L., Ho, B. C., Magnotta, V., Jung, R. E., McCarley, R. W., Schulz, S. C., Lauriello, J., Clark, V. P., Voyvodic, J. T., Diaz, M. T., and Calhoun, V. D. (2009). Voxelbased morphometric multisite collaborative study on schizophrenia, Schizophr. Bull. 35, 82-95.

Seok, J.-H., Park, H.-J., Chun, J.-W., Lee, S.-K., Cho, H. S., Kwon, J. S., and Kim, J.-J. (2007). White matter abnormalities associated with auditory hallucinations in schizophrenia: a combined study of voxelbased analyses of diffusion tensor imaging and structural magnetic resonance imaging. Psychiatry Res. 156, 93-104.

Sheline, Y. I., Barch, D. M., Price, J. L., Rundle, M. M., Vaishnavi, S. N., Snyder, A. Z., Mintun, M. A., Wang, S., Coalson, R. S., and Raichle, M. E. (2009). The default mode network and selfreferential processes in depression. Proc. Natl. Acad. Sci. U.S.A. 106, 1943-1947.

Sheline, Y. I., Price, J. L., Yan, Z., and Mintun, M. A. (2010). Restingstate functional MRI in depression unmasks increase connectivity between networks via the dorsal nexus. Proc. Natl. Acad. Sci. U.S.A. 107, 11020-11025.

Shergill, S. S., Kanaan, R. A., Chitnis, X. A., O’Daly, O., Jones, D. K., Frangou, S., Williams, S. C. R., and Howard, R. J. (2007). A diffusion tensor imaging study of fasciculi in schizophrenia. Am. J. Psychiatry 164, 467-473.

Skelly, L. R., Calhoun, V., Meda, S. A., Kim, J., Mathalon, D. H., and Pearlson, G. D. (2008). Diffusion tensor imaging in schizophrenia: relationship to symptoms. Schizophr. Res. 98, 157-162.

Skudlarski, P., Jagannathan, K., Anderson, K., Stevens, M. C., Calhoun, V. D., Skudlarska, B. A., and Pearlson, G. (2010). Brain connectivity is not only lower but different in schizophrenia: combined anatomical and functional approach. Biol. Psychiatry 68, 61-69.

Smieskova, R., Fusar-Poli, P., Allen, P., Bendfeldt, K., Stieglitz, R. D., Drewe, J., Radu, E. W., McGuire, P. K., Riechler-Rössler, A., and Borgwardt, S. J. (2009). The effects of antipsychotics on the brain 
what have we learnt from structural imaging of schizophrenia? A systematic review. Curr. Pharm. Des. 15, 2535-2549.

Strakowski, S. M., DelBello, M. P., and Adler, C. M. (2005). The functional neuroanatomy of bipolar disorder: a review of neuroimaging findings. Mol. Psychiatry 10, 105-116.

Sui, J., Pearlson, G., Caprihan, A., Adali, T., Kiehl, K. A., Liu, J., Yamamoto, J., and Calhoun, V. D. (2011). Discriminating schizophrenia and bipolar disorder by fusing fMRI and DTI in a multimodal CCA + joint ICA model. Neuroimage 57, 839-855.

Swanson, N., Eichele, T., Pearlson, G., Kiehl, K., Yu, Q., and Calhoun, V. D. (2011). Lateral differences in the default mode network in healthy controls and patients with schizophrenia. Hum. Brain Mapp. 32, 654-664.

Tamminga, C. A., Vogel, M., Gao, X. M., Lahti, A. C., and Holcomb, H. H. (2000). The limbic cortex in schizophrenia: focus on the anterior cingulate. Brain Res. Rev. 31, 364-370.

Théberge, J., Bartha, R., Drost, D. J., Menon, R. S., Malla, A., Takhar, J., Neufeld, R. W. J., Rogers, J., Pavlosky, W., Schaefer, B., Densmore, M., Al-Semaan, Y., and Williamson, P. C. (2002). Glutamate and glutamine measured with 4.0 $\mathrm{T}$ proton MRS in never-treated patients with schizophrenia and healthy volunteers. Am. J. Psychiatry 159, 1944-1946.

Torrey, E. F. (2002). Studies of individuals with schizophrenia never treated with antipsychotic medications: a review. Schizophr. Res. 58, 101-115.

Vedrine, F.-E., Wessa, M., Leboyer, M., and Houenou, J. (2011). A meta-analysis of whole-brain diffusion tensor imaging studies in bipolar disorder. Prog. Neuropsychopharmacol. Biol. Psychiatry 35, 1820-1826.

Veer, I. M., Beckmann, C. F., van Tol, M.-J., Ferrarini, L., Milles, J., Veltman, D. J., Aleman, A., van Buchem, V., van der Wee, N. J., and Rombouts, S. A. R. B. (2010). Whole brain restingstate analysis reveals decreased functional connectivity in major depression. Front. Syst. Neurosci. 4:41. doi: 10.3389/fnsys.2010.00041
Videbech, P., and Ravnkilde, B. (2004). Hippocampal volume and depression: a meta-analysis of MRI studies. Am. J. Psychiatry 161, 1957-1966.

Vita, A., De Peri, L., Silenzi, C., and Dieci, M. (2006). Brain morphology in first-episode schizophrenia: a meta-analysis of quantitative magnetic resonance spectroscopy studies. Schizophr. Res. 82, 75-88.

Wang, L., Metzak, P. D., and Woodward, T. S. (2011). Aberrant connectivity during self-other source monitoring in schizophrenia Schizophr. Res. 125, 136-142.

Welsh, R. C., Chen, A. C., and Taylor, S. F. (2010). Low-frequency BOLD fluctuations demonstrate altered thalamocortical connectivity in schizophrenia. Schizophr. Bull. 36, 713-722.

White, T., Magnotta, V., Bockholt, J., Williams, S., Wallace, S., Ehrlich, S., Mueller, B. A., Ho, B.-C., Jung, R. E., Clark, V. P., Lauriello, J., Bustillo, J., Schulz, S. C., Gollub, R. L., Andreasen, N. C., Calhoun, V. D., and Lim, K. O. (2011). Global white matter abnormalities in schizophrenia: a multisite diffusion tensor imaging study. Schizophr. Bull. 37, 222-232.

White, T., Nelson, M., and Lim, K. O. (2008). Diffusion tensor imaging in psychiatric disorders. Top. Magn. Reson. Imaging 19, 97-109.

White, T. P., Joseph, V., Francis, S. T., and Liddle, P. F. (2010). Aberrant salience network (bilateral insula and anterior cingulate cortex) connectivity during information processing in schizophrenia. Schizophr. Res. 123, 105-115.

Whitfield-Gabrieli, S., Thermenos, H. W., Milanovic, S., Tsuang, M. T., Faraone, S. V., McCarley, R. W., Shenton, M. E., Green, A. I., NietoCastanon, A., LaViolette, P., Wojcik, J., Gabrieli, J. D. E., and Seidman, L. J. (2009). Hyperactivity and hyperconnectivity of the default network in schizophrenia and in first-degree relatives of persons with schizophrenia. Proc. Natl. Acad. Sci. U.S.A. 106, 1279-1284.

Williamson, P. C. (2006). Mind, Brain, and Schizophrenia. New York, NY: Oxford University Press.

Williamson, P. C. (2007). Are anticorrelated networks in the brain relevant to schizophrenia? Schizophr. Bull. 33, 994-1003.
Williamson, P. C., and Allman, J. M. (2011). The Human Illnesses: Neuropsychiatric Disorders and the Nature of the Human Brain. New York, NY: Oxford University Press.

Wolf, N. D., Sambataro, F., Vasic, N., Frasch, K., Schmid, M., Schöenfeldt-Lecuona, C., Thomann, P. A., and Wolf, R. C. (2011). Dysconnectivity of multiple resting-state networks in patients with schizophrenia who have persistent auditory verbal hallucinations. J. Psychiatry Neurosci. 36, 366-374.

Woodward, N. D., Rogers, B., and Heckers, S. (2011). Functional resting-state networks are differentially affected in schizophrenia. Schizophr. Res. 130, 86-93.

Wu, F., Tang, Y., Xu, K., Kong, L., Sun, W., Wang, F., Kong, D., Li, Y., and Liu, Y. (2011). White matter abnormalities in medication-naïve subjects with a single short-duration episode of major depressive disorder. Psychiatry Res. 191, 80-83.

Yukie, M., and Shibata, H. (2009). "Temporocingulate interactions in the monkey," in Cingulate Neurobiology and Disease, ed B. A. Vogt (New York, NY: Oxford University Press), 145-162.

Zanetti, M., Jackowski, M. P., Versace, A., Almeida, J. R. C., Hassel, S., Duran, F., Busatto, G. F., Kupfer, D. J., and Phillips, M. L. (2009). Statedependent microstructural white matter changes in bipolar I depression. Eur. Arch. Psychiatry Clin. Neurosci. 259, 316-328.

Zhang, J., Wang, J., Wu, Q., Kuang, W., Huang, X., He, Y., and Gong, Q. (2011). Disrupted brain connectivity networks in drug-naïve, firstepisode major depressive disorder. Biol. Psychiatry 70, 334-342.

Zhou, Y., Liang, M., Jiang, T., Tian, L., Liu, Y., Liu, Z., Liu, H., and Kuang, F. (2007a). Functional dysconnectivity of the dorsolateral prefrontal cortex in first-episode schizophrenia using resting-state fMRI. Neurosci. Lett. 417, 297-302.

Zhou, Y., Liang, M., Tian, L., Wang, K., Hao, Y., Liu, H., Liu, Z., and Jiang, T. (2007b). Functional disintegration in paranoid schizophrenia using resting-state fMRI. Schizophr. Res. 97, 194-205.

Zhou, Y., Qin, L.-D., Chen, J., Qian, L.-J., Tao, J., Fang, Y.-R., and
Xu, J.-R. (2011). Brain microstructural abnormalities revealed by diffusion tensor images in patients with treatment-resistant depression compared with major depressive disorder before treatment. Eur. J. Radiol. 80, 450-454.

Zhou, Y., Shu, N., Liu, Y., Song, M., Hao, Y., Liu, H., Chunshui, Y., Liu, Z., and Jiang, T. (2008). Altered resting-state functional connectivity and anatomical connectivity of hippocampus in schizophrenia. Schizophr. Res. 100, 120-132.

Zhu, X., Wang, X., Xiao, J., Zhong, M., Liao, J., and Yao, S. (2011). Altered white matter integrity in first-episode, treatment-naïve young adults with major depressive disorder: a tract-based spatial statistics study. Brain Res. 1369 223-229.

Zou, K., Huang, X., Li, T., Gong, Q., Li, Z., Ou-yang, L., Deng, W., Chen, Q. Li, C., Ding, Y., and Sun, X. (2008a). Alterations of white matter integrity in adults with major depressive disorder: a magnetic resonance imaging study. J. Psychiatry Neurosci. 33, 525-530.

Zou, L.-Q., Yuan, H.-S., Pei, X.-L., Dong, W.-T., Liu, P.-C., and Xie, J.-X. (2008b). Diffusion tensor imaging study of the anterior limb of the internal capsules in neuroleptic-naïve schizophrenia. Acad. Radiol. 15, 285-289.

Conflict of Interest Statement: The authors declare that the research was conducted in the absence of any commercial or financial relationships that could be construed as a potential conflict of interest.

Received: 10 November 2011; accepted: 02 June 2012; published online: 21 June 2012.

Citation: Williamson $P C$ and Allman JM (2012) A framework for interpreting functional networks in schizophrenia. Front. Hum. Neurosci. 6:184. doi: 10.3389/fnhum.2012.00184

Copyright (c) 2012 Williamson and Allman. This is an open-access article distributed under the terms of the Creative Commons Attribution Non Commercial License, which permits noncommercial use, distribution, and reproduction in other forums, provided the original authors and source are credited. 